\title{
TrkC-Targeted Kinase Inhibitors And PROTACs
}

\author{
Bosheng Zhao and Kevin Burgess
}

Department of Chemistry, Texas A \& M University, Box 30012, College Station, TX 77842, USA, E-mail: burgess@tamu.edu 


\section{Contents}

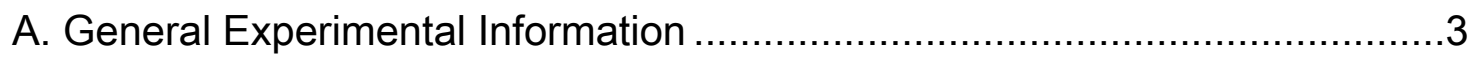

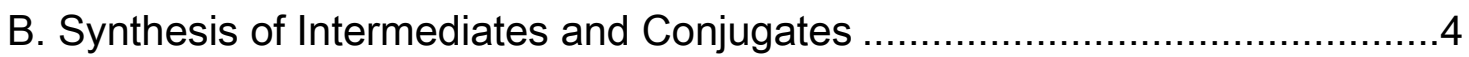

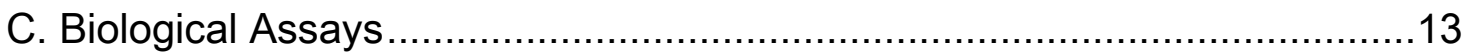

Compound Stability in Serum .........................................................13

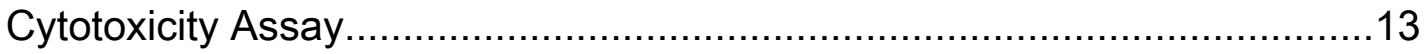

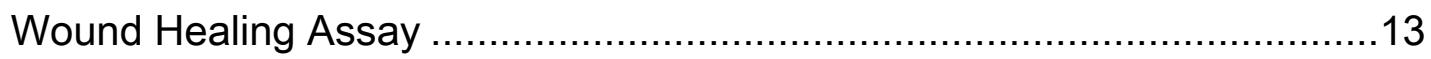

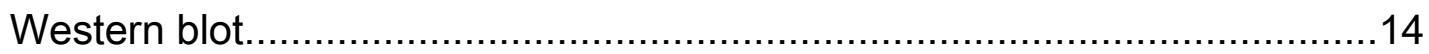

Protein Degradation Assay ...............................................................14

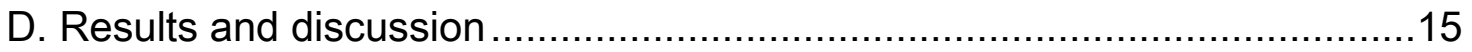

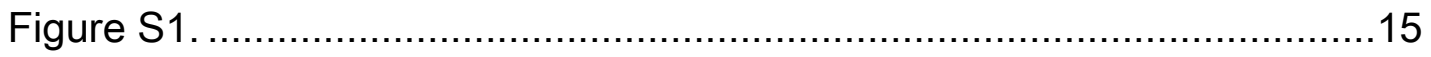

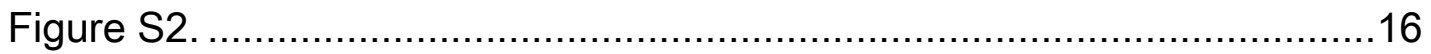

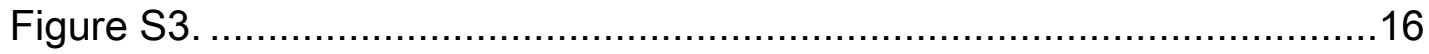

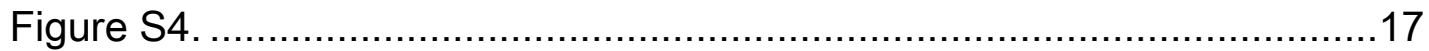

Figure S5.

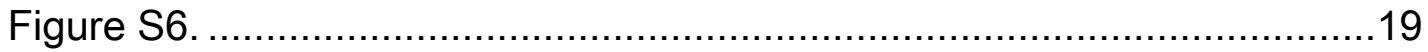

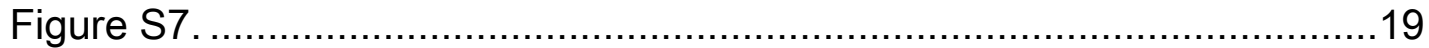

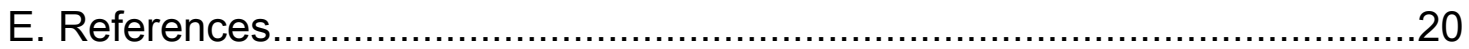

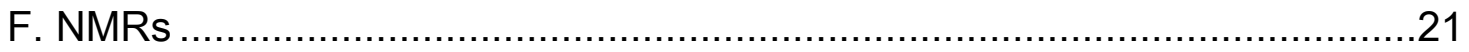




\section{A. General Experimental Information}

All reactions were carried out under an inert atmosphere (nitrogen or argon where stated) with dry solvents under anhydrous conditions. Glassware for anhydrous reactions was dried in an oven at $140^{\circ} \mathrm{C}$ for minimum $6 \mathrm{~h}$ prior to use. Dry solvents were obtained by passing the previously degassed solvents through activated alumina columns. Yields refer to chromatographically and spectroscopically $\left({ }^{1} \mathrm{H}-\right.$ NMR) homogeneous materials, unless otherwise stated. Reagents were purchased at a high commercial quality (typically $97 \%$ or higher) and used without further purification, unless otherwise stated. Analytical thin layer chromatography (TLC) was carried out on Merck silica gel plates with QF-254 indicator and visualized by UV. Flash column chromatography was performed using silica gel 60 (Silicycle, 230-400 mesh). ${ }^{1} \mathrm{H}$ and ${ }^{13} \mathrm{C}$ spectra were recorded on a $400 \mathrm{MHz}$ spectrometer and were calibrated using residual non-deuterated solvent as an internal reference. The following abbreviations or combinations thereof were used to explain the multiplicities: $\mathrm{s}=$ singlet, $\mathrm{d}=$ doublet, $\mathrm{t}=$ triplet, $\mathrm{q}=$ quartet, $\mathrm{m}=$ multiplet, $d d=$ doublet of doublet, $d d d=$ doublet of doublet of doublets.

Dasatinib was purchased from AK Scientific, Inc. Hs578t and MDA-MB-231 (from American Type Culture Collection, ATCC) were cultured on $75 \mathrm{~cm}^{2}$ culture flasks in Dulbecco's Modified Eagle Medium/nutrient mixture F-12 (DMEM/F12, Sigma Chemical, St. Louis, MO) supplemented with 10 \% FBS. MCF-10A (from ATCC) was cultured in Mammary Epithelial Cell Growth Medium Kit (MEGM, catalog No. CC-3150 excluding GA-1000, Lonza/Clonetics Corporation) with $100 \mathrm{ng} / \mathrm{mL}$ cholera toxin (Sigma Aldrich). HUVEC (from ATCC) was cultured in F-12K Medium (ATCC) supplemented with $10 \%$ FBS. NIH3T3-TrkC and NIH3T3 wild-type cells

were cultured according to previous method. [1] Culture-Inserts for wound healing assay were purchased from Ibidi GmbH. Phospho-Src family (Tyr416), Src, TrkC and $\beta$-actin $m A b$ were purchased from Cell Signaling Technology. Goat anti-rabbit $(\mathrm{H}+\mathrm{L})$ secondary antibody (HRP conjugated) were purchased from ThermoFisher Scientific. SuperSignal West Dura Substrate (ThermoFisher Scientific) was used as Western blot substrate. 


\section{B. Synthesis of Intermediates and Conjugates}<smiles>COc1ccc(C2=N[C@@H](c3ccc(Cl)cc3)[C@H](c3ccc(Cl)cc3)N2C(=O)N2CCNC(=O)C2)c(OC(C)C)c1</smiles>

nutlin-3a<smiles>COc1ccc(C2=N[C@@H](c3ccc(Cl)cc3)[C@H](c3ccc(Cl)cc3)N2C(=O)N2CCN(CC(=O)NCCOCCN)C(=O)C2)c(OC(C)C)c1</smiles>

nutlin-PEG(n)- $\mathbf{N}_{3}$

$\mathrm{n}=3,8 ; n=5,9$

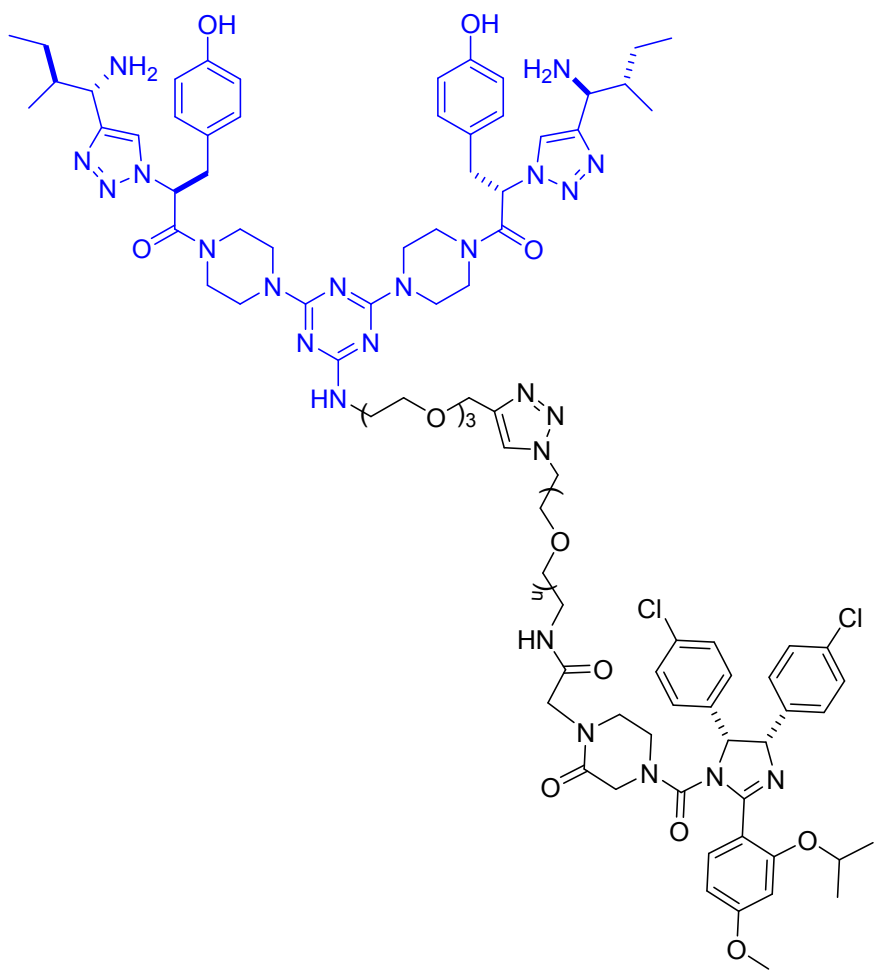

IY-IY-PEG(n)-nutin

$n=3,10 ; n=5,11$ (ii) $\mathrm{Br} \leadsto \mathrm{O} \longrightarrow \mathrm{T}_{\mathrm{n}}$

$25^{\circ} \mathrm{C}, 1.5 \mathrm{~h}$

IY-IY-TEG, $\mathrm{CuSO}_{4}$

$\mathrm{Na}$ ascorbate, TBTA

DMSO : $\mathrm{H}_{2} \mathrm{O}=2: 1$

$25{ }^{\circ} \mathrm{C}, 24 \mathrm{~h}$ (i) $\mathrm{NaH}, \mathrm{DMF}, 0^{\circ} \mathrm{C}, 30 \mathrm{~min}$

Scheme S1. Synthesis of nutlin-PEG(n)- $\mathrm{N}_{3}$ and IY-IY-PEG(n)-nutlin. 
IY-IY-TEG, IY-IY-NH $\mathbf{N}_{2}, \mathrm{YI}-\mathrm{YI}-\mathrm{NH}_{2}$ and $\mathbf{7}$ were made according to previous procedures. ${ }^{[2-4]}$ Das $-\mathbf{N}_{3}$ was made according to literature. ${ }^{[5]}$

Synthesis of 2-(4-(6-((5-((2-chloro-6-methylphenyl)carbamoyl)thiazol-2-yl)amino)2-methylpyrimidin-4-yl)piperazin-1-yl)ethyl 2,2-dimethyl-4,13-dioxo-3-oxa-8,9dithia-5,12-diazahexadecan-16-oate (5)

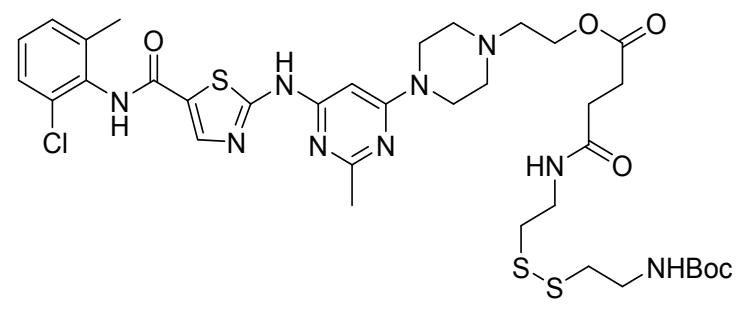

The product of step (i), das- $\mathbf{C O O H}$ was made according to literature. ${ }^{[6]}$ For step (ii), to a solution of tert-butyl (2-((2-aminoethyl)disulfaneyl)ethyl)carbamate $(0.98$ $\mathrm{mmol}$ ) and das-COOH (1.07 mmol) in $10 \mathrm{~mL}$ DMF were added triethylamine (1.96 $\mathrm{mmol})$ and HATU $(1.17 \mathrm{mmol})$. The mixture was stirred for $6 \mathrm{~h}$ at room temperature. Solvent was removed in vacuo. The crude product was purified via column chromatography by eluting with $10 \% \mathrm{MeOH}$ in DCM to obtain 5 as a light yellow solid (680 mg, $84 \%)$.

${ }^{1} \mathrm{H}$ NMR (400 MHz, MeOD) $\delta 8.18(\mathrm{~s}, 1 \mathrm{H}), 7.35$ (dd, J = 7.1, $\left.2.0 \mathrm{~Hz}, 1 \mathrm{H}\right), 7.24(\mathrm{t}$, $J=7.2 \mathrm{~Hz}, 2 \mathrm{H}), 6.32(\mathrm{~s}, 1 \mathrm{H}), 4.54(\mathrm{dd}, J=5.8,3.9 \mathrm{~Hz}, 2 \mathrm{H}), 4.05(\mathrm{~s}, 3 \mathrm{H}), 3.61-$ $3.45(\mathrm{~m}, 8 \mathrm{H}), 3.32-3.28(\mathrm{~m}, 3 \mathrm{H}), 2.80(\mathrm{t}, J=6.7 \mathrm{~Hz}, 2 \mathrm{H}), 2.74(\mathrm{t}, J=6.9 \mathrm{~Hz}$, $2 \mathrm{H}), 2.62(\mathrm{~s}, 4 \mathrm{H}), 2.53(\mathrm{~s}, 3 \mathrm{H}), 2.32(\mathrm{~s}, 3 \mathrm{H}), 1.41(\mathrm{~s}, 9 \mathrm{H})$.

${ }^{13} \mathrm{C}$ NMR $(101 \mathrm{MHz}, \mathrm{MeOD}) \delta 173.3,172.7,165.0,163.8,162.2,161.3,156.9$, $156.5,138.9,132.8,128.8,128.3,126.9,125.7,117.6,114.7,83.5,78.8,57.2$, $55.6,51.5,41.1,39.4,38.3,37.7,37.2,30.1,29.2,27.4,23.5,17.3$.

HRMS (ESI+) $\mathrm{m} / \mathrm{z}$ calcd for $\mathrm{C}_{35} \mathrm{H}_{49} \mathrm{CIN}_{9} \mathrm{O}_{6} \mathrm{~S}_{3}{ }^{+}(\mathrm{M}+\mathrm{H})^{+}$822.2651; found 822.2597. 
Synthesis of 1-(4-(6-((5-((2-chloro-6-methylphenyl)carbamoyl)thiazol-2-yl)amino)2-methylpyrimidin-4-yl)piperazin-1-yl)-4,7,16-trioxo-3-oxa-11,12-dithia-8,15diazanonadecan-19-oic acid (6)<smiles>Cc1nc(Nc2ncc(C(=O)Nc3c(C)cccc3Cl)s2)cc(N2CCN(CCOC(=O)CCC(=O)NCCSSCCNC(=O)CCC(=O)O)CC2)n1</smiles>

$4 \mathrm{M} \mathrm{HCl}$ in dioxane was added to $5(0.4 \mathrm{mmol})$ and stirred for $1 \mathrm{~h}$ at room temperature. Solvent was removed in vacuo. The residue was redissolved in $5 \mathrm{~mL}$ DMF. Triethylamine $(6 \mathrm{mmol})$ and succinic anhydride $(0.52 \mathrm{mmol})$ were added to the solution and stirred for another $12 \mathrm{~h}$ at room temperature. Solvent was removed and the crude product was purified via prep-HPLC to obtain $\mathbf{6}$ as a white solid (214 mg, $65 \%)$.

${ }^{1} \mathrm{H}$ NMR (400 MHz, MeOD) $\delta 8.18(\mathrm{~s}, 1 \mathrm{H}), 7.35$ (dd, $\left.J=7.1,2.0 \mathrm{~Hz}, 1 \mathrm{H}\right), 7.24(\mathrm{t}$, $J=7.2 \mathrm{~Hz}, 2 \mathrm{H}), 6.29(\mathrm{~s}, 1 \mathrm{H}), 4.55(\mathrm{dd}, J=5.8,4.0 \mathrm{~Hz}, 2 \mathrm{H}), 4.18(\mathrm{dd}, J=38.9$, $34.1 \mathrm{~Hz}, 4 \mathrm{H}), 3.63-3.40(\mathrm{~m}, 11 \mathrm{H}), 2.78(\mathrm{dt}, J=15.0,6.7 \mathrm{~Hz}, 5 \mathrm{H}), 2.66-2.42$ $(\mathrm{m}, 14 \mathrm{H}), 2.31(\mathrm{~s}, 3 \mathrm{H})$.

${ }^{13} \mathrm{C}$ NMR $(101 \mathrm{MHz}, \mathrm{MeOD}) \delta 174.9,173.4,173.3,172.8,163.9,162.2,161.3$, $160.1,159.7,138.9,132.8,128.8,128.3,127.0,117.3,114.4,83.5,71.0,57.1$, $55.6,51.6,41.1,38.4,38.3,37.3,37.1,30.2,30.1,29.2,28.9,28.3,17.3$.

HRMS (ESI+) $\mathrm{m} / \mathrm{z}$ calcd for $\mathrm{C}_{34} \mathrm{H}_{45} \mathrm{CIN}_{9} \mathrm{O}_{7} \mathrm{~S}_{3}{ }^{+}(\mathrm{M}+\mathrm{H})^{+}$822.2287; found 822.2244. 
Synthesis of 2-((6-)-(2-)-((2-(2--(2-)(4,6-bis(4-((S)-2-(4-((1S,2S)-1-amino-2methylbutyl)-1H-1,2,3-triazol-1-yl)-3-(4-hydroxyphenyl)propanoyl)piperazin-1-yl)1,3,5-triazin-2-yl)amino)ethoxy)ethoxy)ethoxy)methyl)-1 $\mathrm{H}-1,2,3$-triazol-1yl)ethyl)piperazin-1-yl)-2-methylpyrimidin-4-yl)amino)-N-(2-chloro-6methylphenyl)thiazole-5-carboxamide (IY-IY-das, 1)

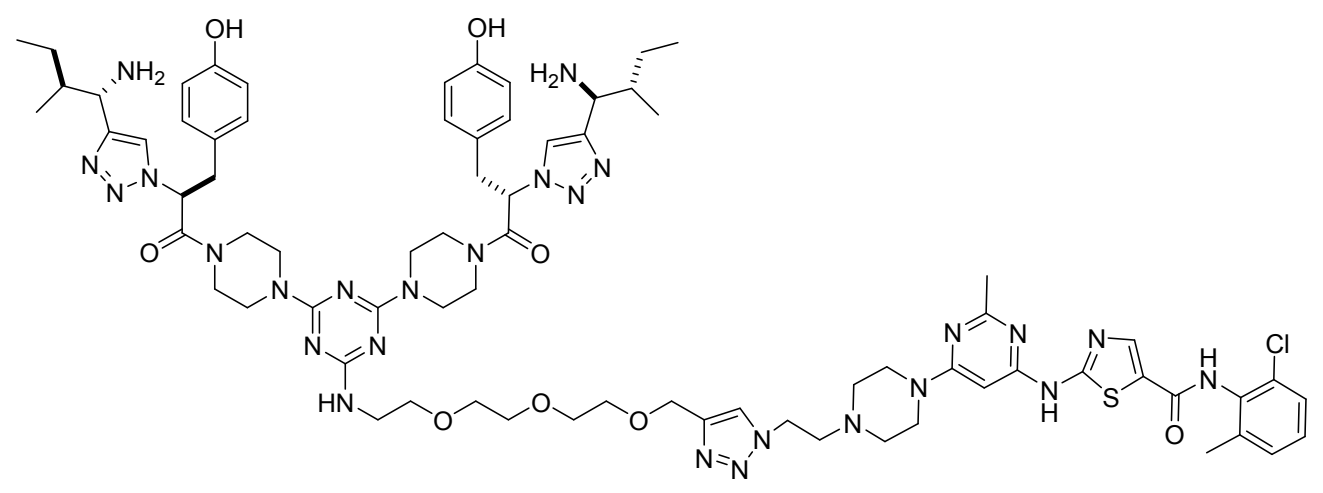

$\mathrm{CuSO}_{4}(3 \mu \mathrm{mol})$, Na ascorbate $(12 \mu \mathrm{mol})$ and TBTA $(3 \mu \mathrm{mol})$ were added to a mixture of IY-IY-TEG $(10 \mu \mathrm{mol})$ and das- $\mathrm{N}_{3}(11 \mu \mathrm{mol})$ in $0.2 \mathrm{~mL}$ DMSO and 0.1 $\mathrm{mL} \mathrm{H}_{2} \mathrm{O}$. The reaction mixure was stirred for $24 \mathrm{~h}$ at room temperature. Solvent was removed and the crude product was purified by prep-HPLC to obtain 1 as white solid (5.4 mg, $35 \%)$.

${ }^{1} \mathrm{H}$ NMR (400 MHz, DMSO-d 6 ) $\delta 9.89$ (s, $\left.1 \mathrm{H}\right), 8.40$ (s, 5H), 8.22 (dd, $J=39.5$, $12.5 \mathrm{~Hz}, 4 \mathrm{H}), 7.40(\mathrm{dd}, J=7.4,1.7 \mathrm{~Hz}, 1 \mathrm{H}), 7.32-7.23(\mathrm{~m}, 2 \mathrm{H}), 6.99(\mathrm{~d}, J=8.5$ $\mathrm{Hz}, 4 \mathrm{H}), 6.61(\mathrm{~d}, \mathrm{~J}=8.4 \mathrm{~Hz}, 4 \mathrm{H}), 6.18(\mathrm{~s}, 3 \mathrm{H}), 4.82(\mathrm{t}, \mathrm{J}=6.4 \mathrm{~Hz}, 3 \mathrm{H}), 4.58-$ $4.49(\mathrm{~m}, 4 \mathrm{H}), 4.41-4.36(\mathrm{~m}, 2 \mathrm{H}), 3.68-3.21(\mathrm{~m}, 42 \mathrm{H}), 2.45(\mathrm{~s}, 3 \mathrm{H}), 2.24(\mathrm{~s}$, $3 \mathrm{H}), 1.99-1.88(\mathrm{~m}, 2 \mathrm{H}), 1.40-1.28(\mathrm{~m}, 2 \mathrm{H}), 1.01(\mathrm{dt}, J=21.9,7.8 \mathrm{~Hz}, 2 \mathrm{H})$, 0.88 (t, $J=7.3 \mathrm{~Hz}, 6 \mathrm{H}), 0.75(\mathrm{~d}, J=6.8 \mathrm{~Hz}, 6 \mathrm{H})$.

${ }^{13} \mathrm{C}$ NMR $\left(101 \mathrm{MHz}, \mathrm{DMSO}-\mathrm{d}_{6}\right) \delta 169.6,166.4,165.9,162.4,158.9,158.6$, 158.2, 157.7, 156.8, 144.8, 142.1, 130.8, 129.5, 128.5, 127.5, 126.5(2C), 126.2, 125.9, 125.7, 125.0, 124.0, 122.7, 115.6, 70.2(2C), 70.0, 69.6, 69.4, 69.2, 51.3, 51.2, 45.4, 43.2, 43.0, 42.8, 41.4, 41.1, 37.7, 37.2, 35.7, 31.1, 26.0, 25.6, 18.7, 14.1, 11.6.

HRMS (ESI+) $\mathrm{m} / \mathrm{z}$ calcd for $\mathrm{C}_{74} \mathrm{H}_{100} \mathrm{CIN}_{26} \mathrm{O}_{8} \mathrm{~S}^{+}(\mathrm{M}+\mathrm{H})^{+}$1547.7621; found 1547.7593. 
Synthesis of 2-(4-(6-((5-((2-chloro-6-methylphenyl)carbamoyl)thiazol-2-yl)amino)2-methylpyrimidin-4-yl)piperazin-1-yl)ethyl 1-((4,6-bis(4-((R)-2-(4-((1R,2R)-1-amino-2-methylbutyl)-1 H-1,2,3-triazol-1-yl)-3-(4-hydroxyphenyl)propanoyl) piperazin1-yl)-1,3,5-triazin-2-yl)amino)-10,13,22-trioxo-3,6-dioxa-17,18-dithia-9,14,21triazapentacosan-25-oate (IY-IY-SS-das, 2)

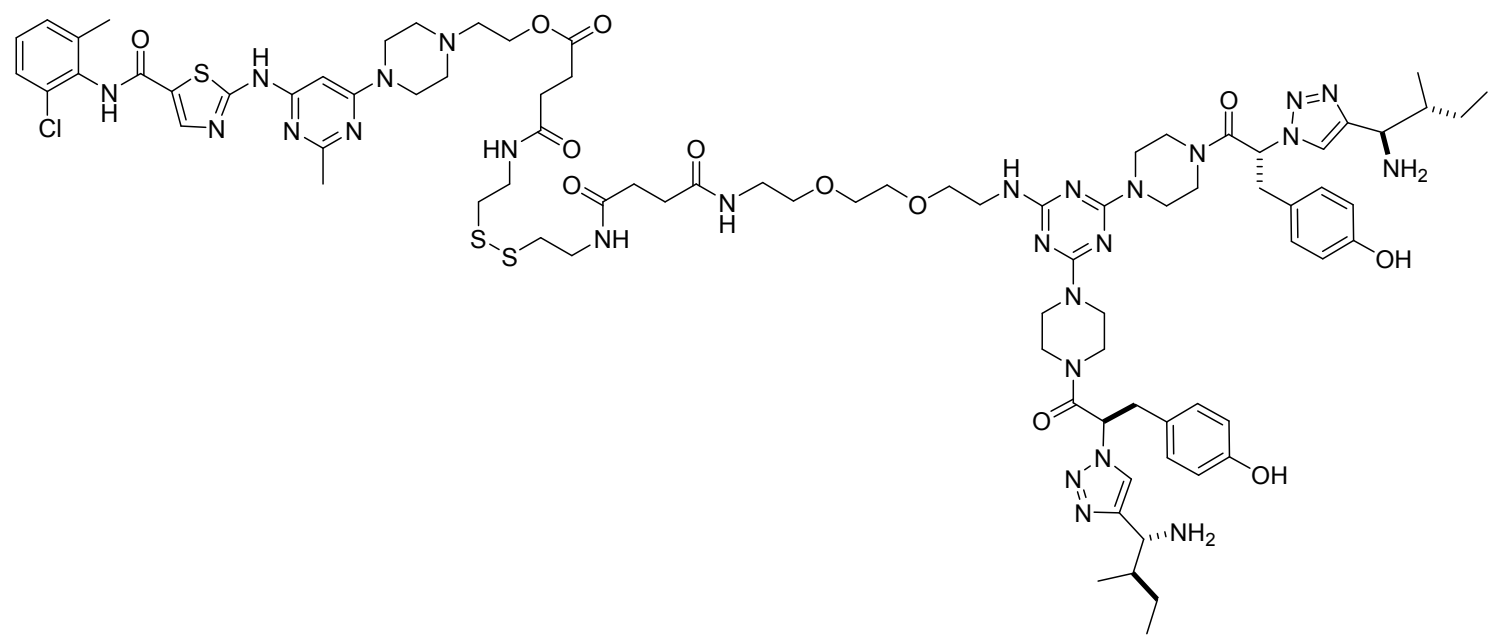

To a solution of $6(67 \mu \mathrm{mol})$ and IY-IY- $\mathrm{NH}_{2}(52 \mu \mathrm{mol})$ in $2.5 \mathrm{~mL}$ DMF were added triethylamine $(130 \mu \mathrm{mol})$ and HATU $(77 \mu \mathrm{mol})$. The mixture was stirred for $12 \mathrm{~h}$ at room temperature. Solvent was removed and the crude product was purified by prep-HPLC. Solvent was removed via lyophilizer. $4 \mathrm{M} \mathrm{HCl}$ in dioxane was added to the remaining solid and stirred for $1 \mathrm{~h}$ at room temperature. Dioxane was removed in vacuo. $\mathrm{H}_{2} \mathrm{O}$ was added and removed via lyophilizer to obtain 2 as white solid (30 mg, $32 \%$ ).

${ }^{1} \mathrm{H}$ NMR $(400 \mathrm{MHz}, \mathrm{MeOD}) \delta 8.25$ (dd, $\left.J=25.5,6.2 \mathrm{~Hz}, 4 \mathrm{H}\right), 7.35$ (dd, $J=6.8,2.2$ $\mathrm{Hz}, 1 \mathrm{H}), 7.24(\mathrm{~d}, J=7.1 \mathrm{~Hz}, 2 \mathrm{H}), 7.05(\mathrm{~s}, 5 \mathrm{H}), 6.69(\mathrm{~d}, J=8.0 \mathrm{~Hz}, 5 \mathrm{H}), 6.58(\mathrm{~s}$, $1 \mathrm{H}), 6.17(\mathrm{~s}, 2 \mathrm{H}), 4.57(\mathrm{~s}, 2 \mathrm{H}), 4.45(\mathrm{~d}, J=6.0 \mathrm{~Hz}, 2 \mathrm{H}), 3.76-3.34(\mathrm{~m}, 52 \mathrm{H}), 2.88$ - $2.76(\mathrm{~m}, 5 \mathrm{H}), 2.71-2.55(\mathrm{~m}, 12 \mathrm{H}), 2.31(\mathrm{~s}, 3 \mathrm{H}), 2.03(\mathrm{~d}, J=6.0 \mathrm{~Hz}, 3 \mathrm{H}), 1.46$ $(\mathrm{d}, J=5.7 \mathrm{~Hz}, 2 \mathrm{H}), 1.19-1.07(\mathrm{~m}, 2 \mathrm{H}), 0.98(\mathrm{t}, J=7.3 \mathrm{~Hz}, 6 \mathrm{H}), 0.86(\mathrm{~d}, J=6.7$ $\mathrm{Hz}, 6 \mathrm{H})$.

${ }^{13} \mathrm{C}$ NMR (101 MHz, MeOD) $\delta$ 174.4, 174.2, 174.0, 173.3, 173.1, 172.6, 167.0, 164.4, 160.6, 159.7, 156.7, 155.7, 154.0, 142.9, 142.6, 141.7, 138.8, 132.7, 132.4, $130.3,128.9,127.0,126.6,125.7,125.5,123.7,115.2,72.2,71.1,70.2,70.0,68.9$, $68.4,60.8,60.7,57.5,51.6,51.3,42.4,40.5,39.6,38.6,37.7,37.6,36.9,30.5$, $30.4,30.2,29.3,28.8,25.3,21.2,17.3(2 \mathrm{C}), 13.1,10.1$.

HRMS (MALDI+) m/z calcd for $\mathrm{C}_{83} \mathrm{H}_{117} \mathrm{CIN}_{26} \mathrm{O}_{12} \mathrm{~S}_{3}{ }^{2+}(\mathrm{M}+2 \mathrm{H})^{2+}$ 900.4092; found 900.4090. 
Synthesis of 2-(4-(6-((5-((2-chloro-6-methylphenyl)carbamoyl)thiazol-2-yl)amino)2-methylpyrimidin-4-yl)piperazin-1-yl)ethyl 1-((4,6-bis(4-((2S,3S)-2-(4-((S)-1amino-2-(4-hydroxyphenyl)ethyl)-1H-1,2,3-triazol-1-yl)-3-methylpentanoyl) piperazin-1-yl)-1,3,5-triazin-2-yl)amino)-10,13,22-trioxo-3,6-dioxa-17,18-dithia9,14,21-triazapentacosan-25-oate (YI-YI-SS-das, 3)

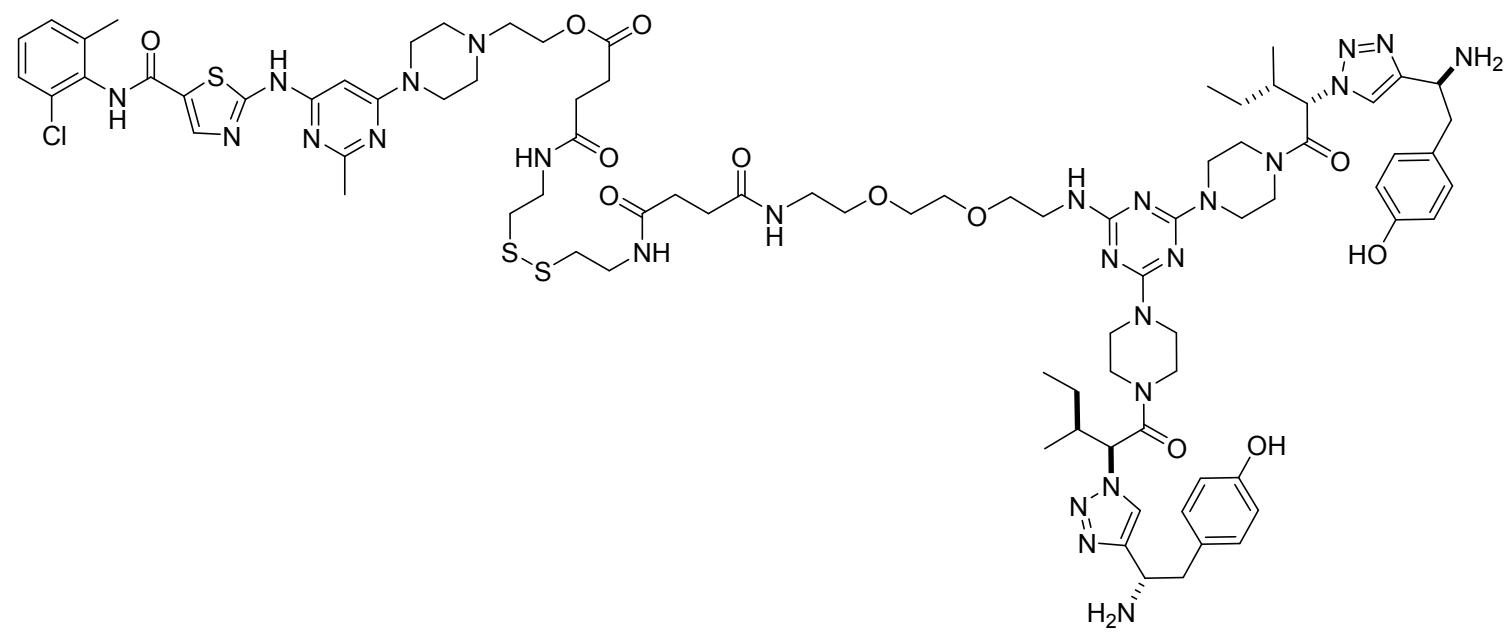

$\mathbf{3}$ was synthesized in a similar way as $\mathbf{2}$ by using YI-YI- $\mathbf{N H}_{\mathbf{2}}$ instead of IY-IY- $\mathbf{N H}_{\mathbf{2}}$. White solid (36 mg, $35 \%$ ).

${ }^{1} \mathrm{H}$ NMR $(400 \mathrm{MHz}$, DMSO-d 6 ) $\delta 10.33$ (s, 1H), 8.80 (s, 7H), 8.51 (s, 3H), 8.15 (dd, $J=71.3,51.1 \mathrm{~Hz}, 9 \mathrm{H}), 7.37(\mathrm{~d}, J=7.3 \mathrm{~Hz}, 1 \mathrm{H}), 7.26(\mathrm{t}, J=8.3 \mathrm{~Hz}, 2 \mathrm{H}), 6.85(\mathrm{~d}, J$ $=8.1 \mathrm{~Hz}, 4 \mathrm{H}), 6.57(\mathrm{dd}, J=16.5,9.1 \mathrm{~Hz}, 5 \mathrm{H}), 5.68(\mathrm{~d}, J=9.1 \mathrm{~Hz}, 2 \mathrm{H}), 4.51(\mathrm{~d}, J$ $=46.8 \mathrm{~Hz}, 5 \mathrm{H}), 3.75-3.44(\mathrm{~m}, 30 \mathrm{H}), 3.21(\mathrm{dd}, J=56.5,15.9 \mathrm{~Hz}, 13 \mathrm{H}), 2.76(\mathrm{dd}$, $J=12.8,6.3 \mathrm{~Hz}, 3 \mathrm{H}), 2.58(\mathrm{~s}, 4 \mathrm{H}), 2.43(\mathrm{t}, J=6.7 \mathrm{~Hz}, 2 \mathrm{H}), 2.31(\mathrm{~s}, 3 \mathrm{H}), 2.24(\mathrm{~s}$, $3 \mathrm{H}), 0.97-0.72(\mathrm{~m}, 18 \mathrm{H})$.

${ }^{13} \mathrm{C}$ NMR $(101 \mathrm{MHz}$, DMSO-d 6 ) $\delta 172.5,172.0(2 \mathrm{C}), 171.4,166.5,166.3,163.6$, 161.2, 159.7, 157.0, 156.7, 156.5, 153.9, 144.0, 141.5, 139.2, 136.6, 133.8, 133.0, $130.7,129.5,128.7,127.7,127.5,126.2,123.8,115.5,72.6,71.0,70.1,70.0,69.5$, $68.7,63.1,60.6,58.7,54.5,50.9,48.8,44.1,42.3,42.0,39.1,38.5,38.2,37.7$, $31.3,31.2,30.3,29.6,24.2,23.9,18.8,15.6,15.5,11.1$.

HRMS (MALDI+) m/z calcd for $\mathrm{C}_{83} \mathrm{H}_{117} \mathrm{CIN}_{26} \mathrm{O}_{12} \mathrm{~S}_{3}{ }^{2+}(\mathrm{M}+2 \mathrm{H})^{2+}$ 900.4092; found 900.4086 . 
Synthesis of 6-(4-((2-(2-(2-)(4,6-bis(4-((S)-2-(4-((1S,2S)-1-amino-2-methylbutyl)1H-1,2,3-triazol-1-yl)-3-(4-hydroxyphenyl)propanoyl)piperazin-1-yl)-1,3,5-triazin2-yl)amino)ethoxy)ethoxy)ethoxy)methyl)-1H-1,2,3-triazol-1-yl)-N-(2-(2,6dioxopiperidin-3-yl)-1,3-dioxoisoindolin-4-yl)hexanamide (IY-IY-pom, 4)

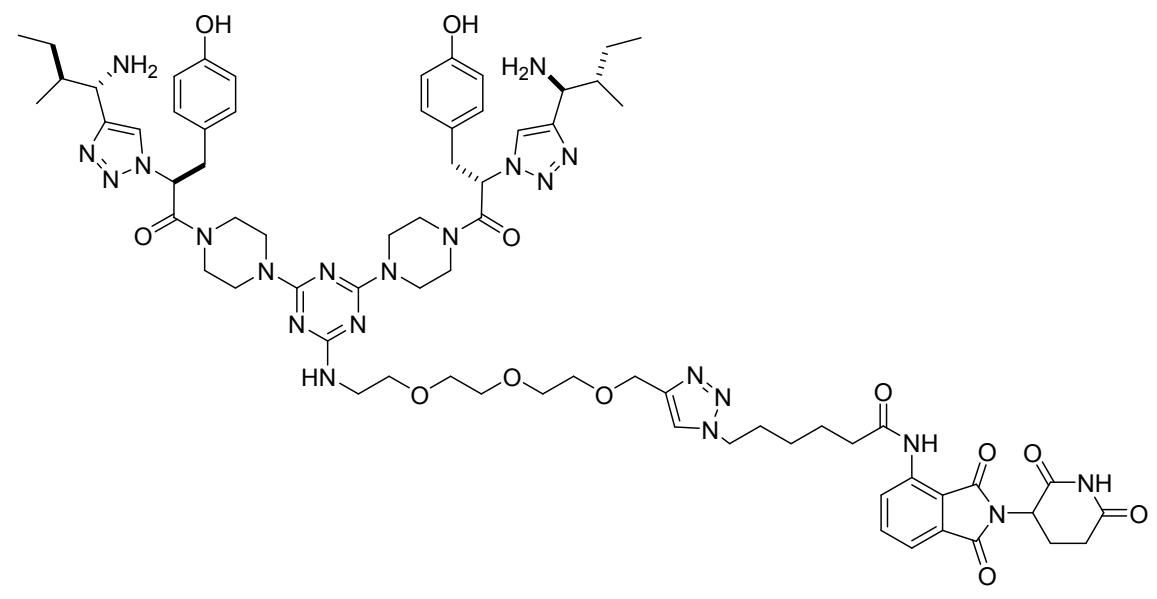

$\mathrm{CuSO}_{4}(4 \mu \mathrm{mol}), \mathrm{Na}$ ascorbate $(16 \mu \mathrm{mol})$ and TBTA $(4 \mu \mathrm{mol})$ were added to a mixture of IY-IY-TEG $(13.2 \mu \mathrm{mol})$ and $7(14.6 \mu \mathrm{mol})$ in $0.3 \mathrm{~mL}$ DMSO and $0.15 \mathrm{~mL}$ $\mathrm{H}_{2} \mathrm{O}$. The reaction mixture was stirred for $24 \mathrm{~h}$ at room temperature. Solvent was removed and the crude product was purified by prep-HPLC to obtain 4 as white solid (7.3 mg, $32 \%)$.

${ }^{1} \mathrm{H}$ NMR $\left(400 \mathrm{MHz}, \mathrm{DMSO}_{\mathrm{d}}\right) \delta 11.11(\mathrm{~s}, 1 \mathrm{H}), 9.67(\mathrm{~s}, 1 \mathrm{H}), 8.48-8.40(\mathrm{~m}, 6 \mathrm{H})$, $8.29(\mathrm{~s}, 2 \mathrm{H}), 8.07(\mathrm{~s}, 1 \mathrm{H}), 7.84-7.79(\mathrm{~m}, 1 \mathrm{H}), 7.60(\mathrm{~d}, J=7.0 \mathrm{~Hz}, 1 \mathrm{H}), 6.99(\mathrm{~d}, J$ $=8.4 \mathrm{~Hz}, 4 \mathrm{H}), 6.61(\mathrm{~d}, J=8.4 \mathrm{~Hz}, 4 \mathrm{H}), 6.16(\mathrm{~s}, 2 \mathrm{H}), 5.14(\mathrm{dd}, J=12.8,5.4 \mathrm{~Hz}$, $1 \mathrm{H}), 4.50(\mathrm{~d}, J=3.7 \mathrm{~Hz}, 3 \mathrm{H}), 4.36(\mathrm{dt}, J=14.2,6.1 \mathrm{~Hz}, 4 \mathrm{H}), 3.63-3.38(\mathrm{~m}, 30 \mathrm{H})$, $3.27(\mathrm{dd}, J=15.6,7.5 \mathrm{~Hz}, 4 \mathrm{H}), 2.96-2.83(\mathrm{~m}, 1 \mathrm{H}), 2.61(\mathrm{~d}, J=18.2 \mathrm{~Hz}, 1 \mathrm{H}), 2.54$ (dd, $J=8.7,4.6 \mathrm{~Hz}, 1 \mathrm{H}), 2.46(\mathrm{t}, J=7.4 \mathrm{~Hz}, 2 \mathrm{H}), 2.07(\mathrm{t}, J=5.2 \mathrm{~Hz}, 1 \mathrm{H}), 1.98-$ $1.80(\mathrm{~m}, 4 \mathrm{H}), 1.72-1.60(\mathrm{~m}, 2 \mathrm{H}), 1.40-1.26(\mathrm{~m}, 4 \mathrm{H}), 0.99(\mathrm{dt}, J=21.9,7.1 \mathrm{~Hz}$, $2 \mathrm{H}), 0.88(\mathrm{t}, J=7.3 \mathrm{~Hz}, 6 \mathrm{H}), 0.75(\mathrm{~d}, J=6.7 \mathrm{~Hz}, 6 \mathrm{H})$.

${ }^{13} \mathrm{C}$ NMR $(101 \mathrm{MHz}$, DMSO-d 6 ) $\delta 172.7,171.8,169.7,167.7,166.6,165.9,158.5$, 158.2, 156.3, 143.8, 141.6, 136.5, 136.0, 131.4, 130.3, 126.3, 125.4, 123.7, 123.5, $118.3,117.0,115.1,69.7(2 \mathrm{C}), 69.5(2 \mathrm{C}), 68.9,68.8,63.5,50.7,49.1,48.9,42.4$, $37.2,37.1,36.2,30.9(2 \mathrm{C}), 29.4,25.3,25.1,24.1,22.0,13.7,11.1$.

HRMS (MALDI+) $\mathrm{m} / \mathrm{z}$ calcd for $\mathrm{C}_{71} \mathrm{H}_{95} \mathrm{~N}_{22} \mathrm{O}_{12}{ }^{+}(\mathrm{M}+\mathrm{H})^{+}$1447.7494; found 1447.7622 . 
Synthesis of N-(2-(2-(2-(2-)-((2-(2--(2-)(4,6-bis(4-((S)-2-(4-((1S,2S)-1-amino-2methylbutyl)-1H-1,2,3-triazol-1-yl)-3-(4-hydroxyphenyl)propanoyl)piperazin-1-yl)1,3,5-triazin-2-yl)amino)ethoxy)ethoxy)ethoxy)methyl)-1 H-1,2,3-triazol-1yl)ethoxy)ethoxy)ethoxy)ethyl)-2-(4-((4S,5R)-4,5-bis(4-chlorophenyl)-2-(2isopropoxy-4-methoxyphenyl)-4,5-dihydro-1H-imidazole-1-carbonyl)-2oxopiperazin-1-yl)acetamide (IY-IY-PEG3-nutlin, 10)

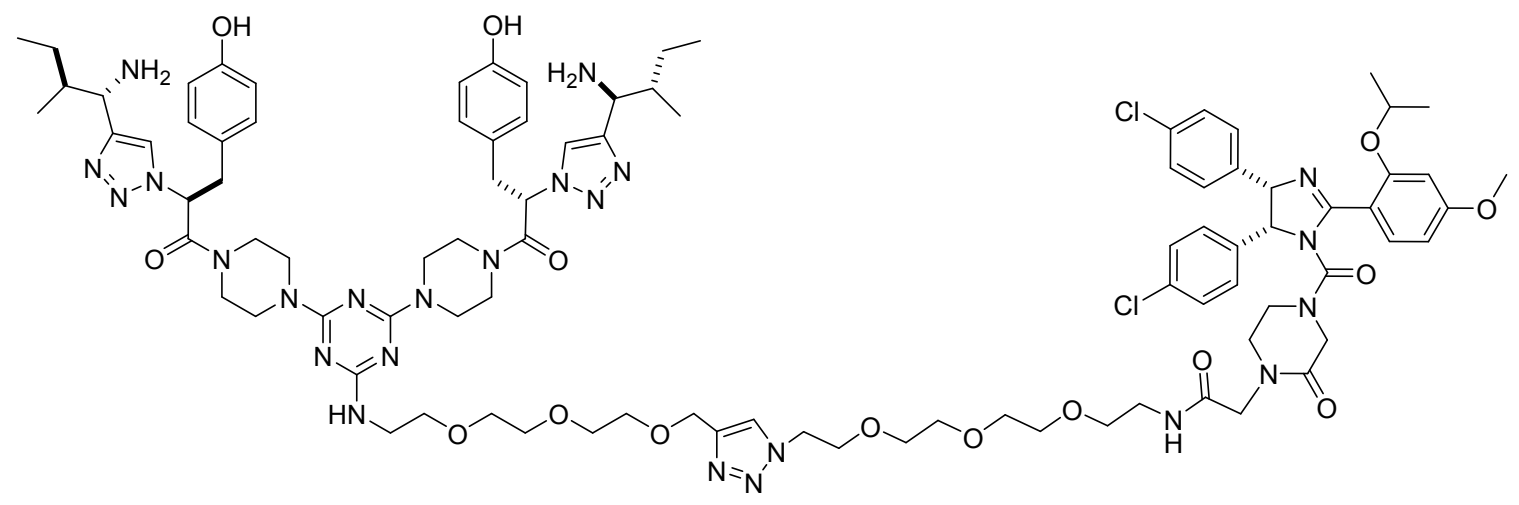

$\mathrm{CuSO}_{4}(2.6 \mu \mathrm{mol}), \mathrm{Na}$ ascorbate $(10.4 \mu \mathrm{mol})$ and TBTA $(2.6 \mu \mathrm{mol})$ were added to a mixture of IY-IY-TEG $(8.6 \mu \mathrm{mol})$ and $8(9.5 \mu \mathrm{mol})$ in $0.2 \mathrm{~mL}$ DMSO and $0.1 \mathrm{~mL}$ $\mathrm{H}_{2} \mathrm{O}$. The reaction mixture was stirred for $24 \mathrm{~h}$ at room temperature. Solvent was removed and the crude product was purified by prep-HPLC to obtain 10 as white solid (5.0 mg, $31 \%)$.

${ }^{1} \mathrm{H}$ NMR (400 MHz, DMSO-d $\left.{ }_{6}\right) \delta 8.42(\mathrm{~s}, 5 \mathrm{H}), 8.29(\mathrm{~s}, 2 \mathrm{H}), 8.05-7.94(\mathrm{~m}, 2 \mathrm{H})$, $7.64(\mathrm{~d}, J=9.2 \mathrm{~Hz}, 1 \mathrm{H}), 7.24(\mathrm{~d}, J=8.5 \mathrm{~Hz}, 2 \mathrm{H}), 7.19(\mathrm{~d}, J=8.5 \mathrm{~Hz}, 2 \mathrm{H}), 7.12(\mathrm{~d}$, $J=8.5 \mathrm{~Hz}, 2 \mathrm{H}), 7.01(\mathrm{dd}, J=13.1,8.5 \mathrm{~Hz}, 6 \mathrm{H}), 6.74(\mathrm{~d}, J=5.5 \mathrm{~Hz}, 2 \mathrm{H}), 6.62(\mathrm{~d}$, $J=8.4 \mathrm{~Hz}, 4 \mathrm{H}), 6.21-6.12(\mathrm{~m}, 2 \mathrm{H}), 5.96(\mathrm{dd}, J=47.1,9.8 \mathrm{~Hz}, 2 \mathrm{H}), 4.90-4.80$ $(\mathrm{m}, 1 \mathrm{H}), 4.51(\mathrm{dd}, J=7.5,4.5 \mathrm{~Hz}, 5 \mathrm{H}), 4.39(\mathrm{~s}, 2 \mathrm{H}), 3.89(\mathrm{~s}, 3 \mathrm{H}), 3.83-3.73(\mathrm{~m}$, $8 \mathrm{H}), 3.56-3.18(\mathrm{~m}, 49 \mathrm{H}), 1.98-1.89(\mathrm{~m}, 2 \mathrm{H}), 1.33(\mathrm{~d}, J=6.0 \mathrm{~Hz}, 3 \mathrm{H}), 1.28(\mathrm{~d}, J$ $=6.0 \mathrm{~Hz}, 3 \mathrm{H}), 1.09-0.93(\mathrm{~m}, 2 \mathrm{H}), 0.88(\mathrm{t}, J=7.3 \mathrm{~Hz}, 6 \mathrm{H}), 0.76(\mathrm{~d}, J=6.7 \mathrm{~Hz}$, $6 \mathrm{H})$.

HRMS (MALDI+) m/z calcd for $\mathrm{C}_{92} \mathrm{H}_{123} \mathrm{Cl}_{2} \mathrm{~N}_{24} \mathrm{O}_{15}{ }^{+}(\mathrm{M}+\mathrm{H})^{+}$1873.8971; found 1873.8943. 
Synthesis of N-(17-(4-((2-(2-(2-)(4,6-bis(4-((S)-2-(4-((1S,2S)-1-amino-2methylbutyl)-1H-1,2,3-triazol-1-yl)-3-(4-hydroxyphenyl)propanoyl)piperazin-1-yl)1,3,5-triazin-2-yl)amino)ethoxy)ethoxy)ethoxy)methyl)-1 $\mathrm{H}-1,2,3$-triazol-1-yl)3,6,9,12,15-pentaoxaheptadecyl)-2-(4-((4S,5R)-4,5-bis(4-chlorophenyl)-2-(2isopropoxy-4-methoxyphenyl)-4,5-dihydro-1 H-imidazole-1-carbonyl)-2oxopiperazin-1-yl)acetamide (IY-IY-PEG5-nutlin, 11)

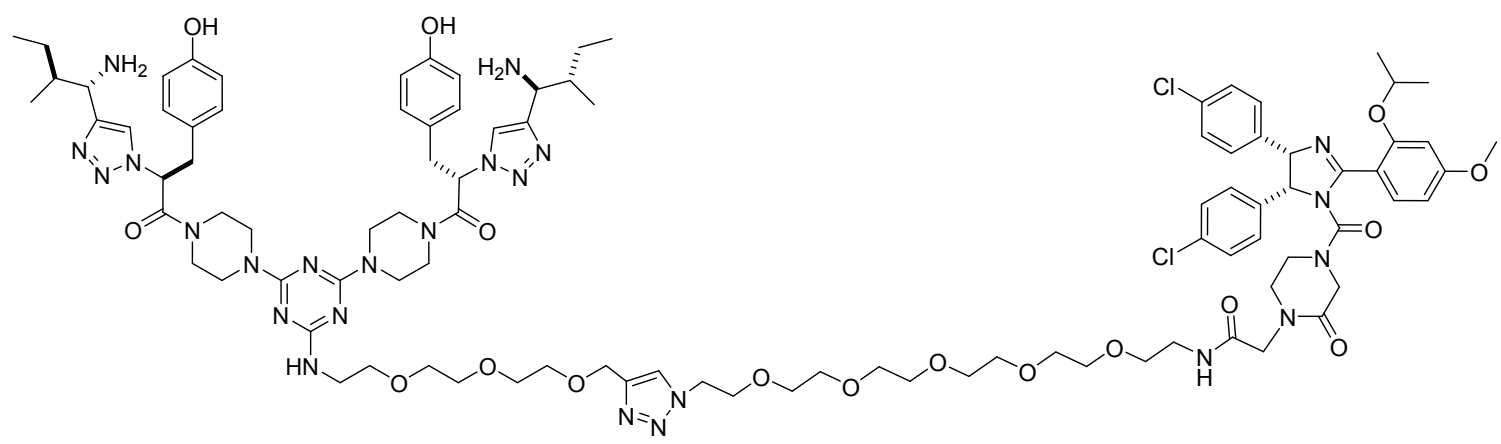

$\mathrm{CuSO}_{4}(2.6 \mu \mathrm{mol}), \mathrm{Na}$ ascorbate $(10.4 \mu \mathrm{mol})$ and TBTA $(2.6 \mu \mathrm{mol})$ were added to a mixture of IY-IY-TEG $(8.6 \mu \mathrm{mol})$ and $9(9.5 \mu \mathrm{mol})$ in $0.2 \mathrm{~mL}$ DMSO and $0.1 \mathrm{~mL}$ $\mathrm{H}_{2} \mathrm{O}$. The reaction mixture was stirred for $24 \mathrm{~h}$ at room temperature. Solvent was removed and the crude product was purified by prep-HPLC to obtain 11 as white solid (5.9 mg, $35 \%$ ).

${ }^{1} \mathrm{H}$ NMR $\left(400 \mathrm{MHz}\right.$, DMSO-d $\left.\mathrm{d}_{6}\right) \delta 8.45-8.27(\mathrm{~m}, 8 \mathrm{H}), 8.03(\mathrm{~s}, 1 \mathrm{H}), 7.92(\mathrm{~s}, 1 \mathrm{H})$, $7.65(\mathrm{~d}, J=8.3 \mathrm{~Hz}, 1 \mathrm{H}), 7.53-7.30(\mathrm{~m}, 7 \mathrm{H}), 6.99(\mathrm{~d}, J=8.5 \mathrm{~Hz}, 4 \mathrm{H}), 6.78-6.68$ $(\mathrm{m}, 3 \mathrm{H}), 6.61(\mathrm{~d}, J=8.4 \mathrm{~Hz}, 4 \mathrm{H}), 6.21-6.11(\mathrm{~m}, 2 \mathrm{H}), 5.35-5.15(\mathrm{~m}, 2 \mathrm{H}), 4.75$ $(\mathrm{dt}, J=12.2,6.1 \mathrm{~Hz}, 1 \mathrm{H}), 4.50(\mathrm{dd}, J=7.8,4.5 \mathrm{~Hz}, 5 \mathrm{H}), 4.38(\mathrm{~s}, 2 \mathrm{H}), 3.86(\mathrm{~s}, 3 \mathrm{H})$, $3.83-3.78(\mathrm{~m}, 4 \mathrm{H}), 3.49-3.15(\mathrm{~m}, 56 \mathrm{H}), 2.04-1.90(\mathrm{~m}, 4 \mathrm{H}), 1.39-1.32(\mathrm{~m}$, $2 \mathrm{H}), 1.24(\mathrm{~d}, J=2.0 \mathrm{~Hz}, 6 \mathrm{H}), 1.04-0.95(\mathrm{~m}, 2 \mathrm{H}), 0.88(\mathrm{t}, J=7.3 \mathrm{~Hz}, 6 \mathrm{H}), 0.75(\mathrm{~d}$, $J=6.8 \mathrm{~Hz}, 6 \mathrm{H})$.

HRMS (MALDI+) m/z calcd for $\mathrm{C}_{96} \mathrm{H}_{132} \mathrm{Cl}_{2} \mathrm{~N}_{24} \mathrm{O}_{17}{ }^{2+}(\mathrm{M}+2 \mathrm{H})^{2+}$ 981.4784; found 981.4764 . 


\section{Biological Assays}

\section{Compound Stability in Serum}

Conjugates (1-3, stock in DMSO) were added in mouse serum/PBS (1:1) at a concentration of $50 \mu \mathrm{M}$. The mixture was incubated at $37^{\circ} \mathrm{C}$ and examined by analytical-HPLC at different time points up to $48 \mathrm{~h}$.

\section{Cytotoxicity Assay}

Cells were seeded in 96-well plate (typically 5,000 cells/well, 3,000 cells/well for Hs578t cells) in $50 \mu \mathrm{L}$ corresponding growth media and allowed to adhere overnight. Compounds were diluted in another $50 \mu \mathrm{L}$ PFHM-II media (for MCF-10A cells use growth media MEGM instead) and added to each well. Cells were incubated for $72 \mathrm{~h}$ before AlamarBlue reagent (Invitrogen) was added. Cells were incubated for an additional $2 \mathrm{~h}$ and fluorescence intensity (Ex/Em 560/590 nm) was measured by a BioTek Synergy 4 Microplate Reader. Cell viabilities are calculated as: $\%$ live cells $=\mathrm{OD}_{\text {compound }} / \mathrm{OD}_{\mathrm{DMSO}} \times 100$. Results are processed by GraphPad Prism 6.0 software.

\section{Wound Healing Assay}

Cells were seeded in 24-well plates using "culture-inserts 2 well" from Ibidi according to manufacturer's instruction (apply $70 \mu \mathrm{L} /$ insert at density of: $3 \times 10^{5}$ cells $/ \mathrm{mL}$ for Hs578t, $7 \times 10^{5}$ cells $/ \mathrm{mL}$ for MDA-MB-231). Cells were allowed to adhere to plate overnight. Culture-inserts were removed and the culture media were replaced by fresh media with compounds (DMSO $=0.2 \%)$. Cells were imaged in brightfield every 30 min under EVOS Auto FI 2 microscope. Images were processed and quantified via "Wound Healing ACAS Image Analysis" from Ibidi/MetaVì Labs online software. 


\section{Western blot}

Cells were seeded in 24-well plate $(50,000$ cells/well for Hs578t, 80,000 cells/well for MDA-MB-231) and allowed to adhere overnight. Culturing media were replaced by fresh media with compounds at desired concentrations (DMSO $<0.5 \%$ ). Cells were incubated for $18 \mathrm{~h}$ before lysed by RIPA buffer (Pierce) according to manufacturer's instructions. Total protein concentrations were determined and calibrated by BCA protein assay (Pierce). Whole cell lysates were subjected to SDS-PAGE, transferred to PVDF membrane and proceeded to Western blot protocol: membrane was blocked with SuperBlock (TBS) Blocking Buffer (ThermoFisher Scientific) for $1 \mathrm{~h}$ at room temperature, incubated with primary antibodies overnight at $4{ }^{\circ} \mathrm{C}$, washed with TBS-T (TBS $+0.05 \%$ Tween 20$) 3$ times, incubated with secondary antibodies for $1 \mathrm{~h}$ at room temperature, washed with TBS-T 4-6 times. Afterwards, blots were treated with SuperSignal West Dura Substrate (ThermoFisher Scientific) and imaged by ChemiDoc XRS (BioRad) imaging system.

Dilution factor: anti-phospho-Src (Tyr 416) mAb (1:1000), anti-Src mAb (1:5000), anti-b-actin mAb (1:5000), HRP-conjugated anti-rabbit IgG $(\mathrm{H}+\mathrm{L})(1: 75,000)$.

\section{Protein Degradation Assay}

Cells were seeded in 24 -well plate $(50,000$ cells/well for Hs $578 t, 100,000$ cells/well for NIH3T3-TrkC) and allowed to adhere overnight. Culturing media were replaced by fresh media with PROTACs (DMSO $<0.5 \%$ ). Cells were incubated for certain time (varies in different experiments) before lysed by RIPA buffer (Pierce) according to manufacturer's instructions. Total protein concentrations were determined and calibrated by BCA protein assay (Pierce). Whole cell lysates were subjected to SDS-PAGE, transferred to PVDF membrane and proceeded to Western blot protocol: membrane was blocked with SuperBlock (TBS) Blocking Buffer (ThermoFisher Scientific) for $1 \mathrm{~h}$ at room temperature, incubated with primary antibodies overnight at $4{ }^{\circ} \mathrm{C}$, washed with TBS-T (TBS $+0.05 \%$ Tween 20) 3 times, incubated with secondary antibodies for $1 \mathrm{~h}$ at room temperature, washed with TBS-T 4-6 times. Afterwards, blots were treated with SuperSignal West Dura Substrate (ThermoFisher Scientific) and imaged by ChemiDoc XRS (BioRad) imaging system.

For time course study, cells were treated with PROTACs or DMSO for different time period before cell lysis.

Dilution factor: anti-TrkC mAb (1:1000), anti-b-actin mAb (1:5000), HRPconjugated anti-rabbit IgG $(\mathrm{H}+\mathrm{L})(1: 75,000)$. 


\section{Results and discussion}
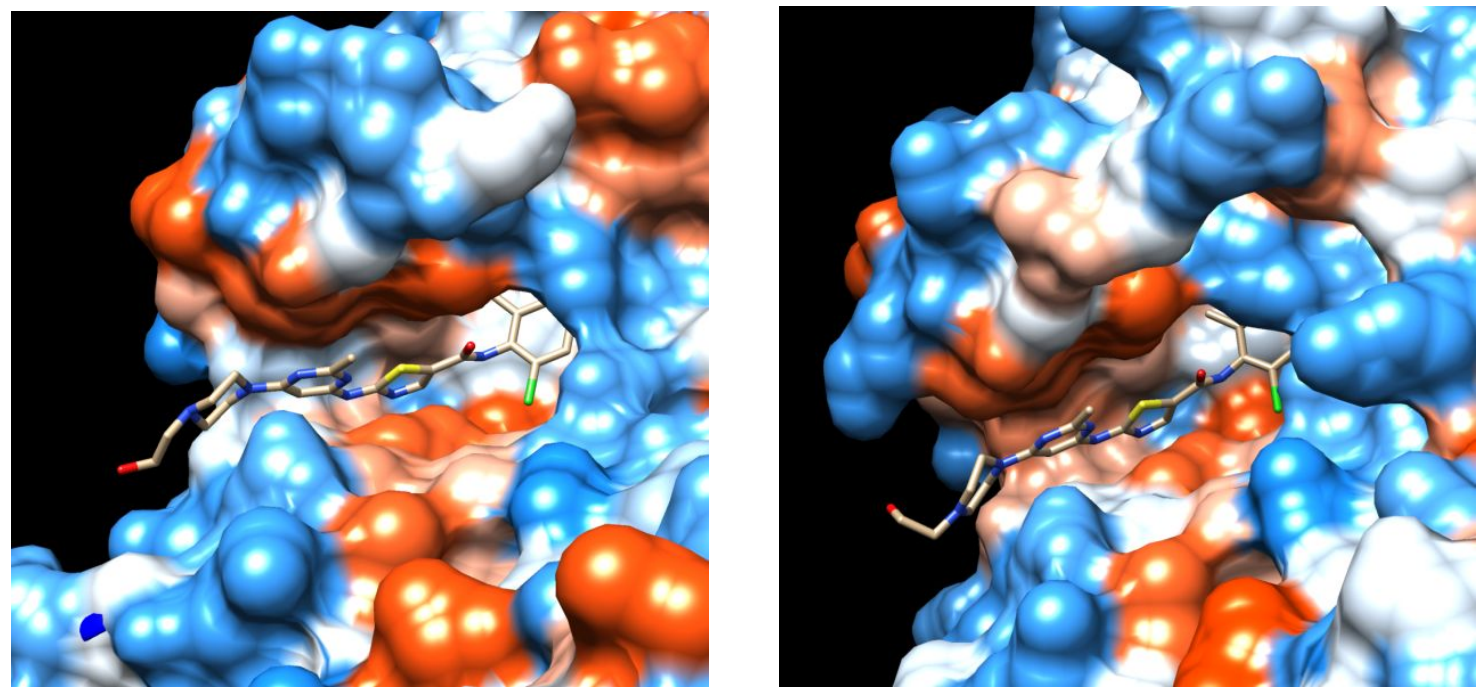

Figure S1. Crystal structure of Dasatinib in complex with c-Src (left, PDB: 3G5D) and Lyn (right, PDB: 2ZVA).

IY-IY-Das, 1

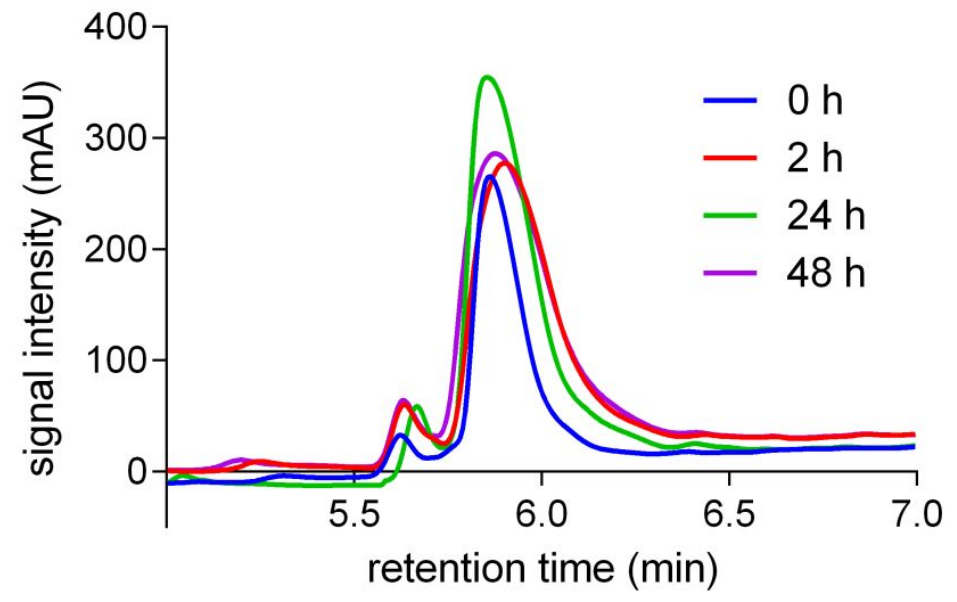




\section{IY-IY-SS-Das, 2}

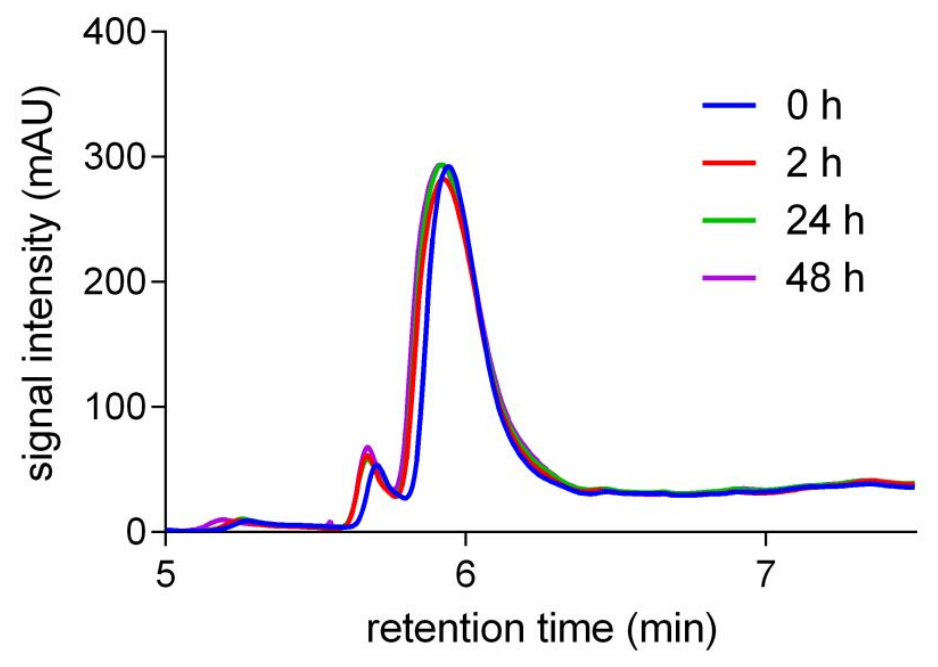

\section{YI-YI-SS-Das, 3}

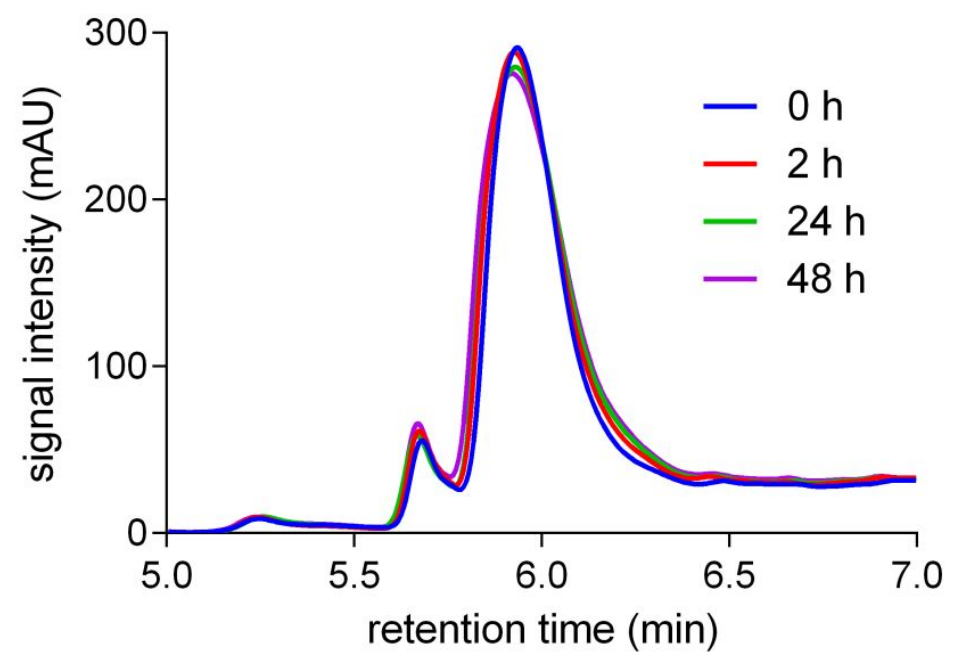

Figure S2. Stabilities of conjugates $\mathbf{1}-\mathbf{3}$ in $1: 1$ mouse serum/PBS at $37^{\circ} \mathrm{C}$.

\section{5 kDa -}

Figure S3. Western blot analysis on TrkC expression in Hs578t cells (in duplicate). 

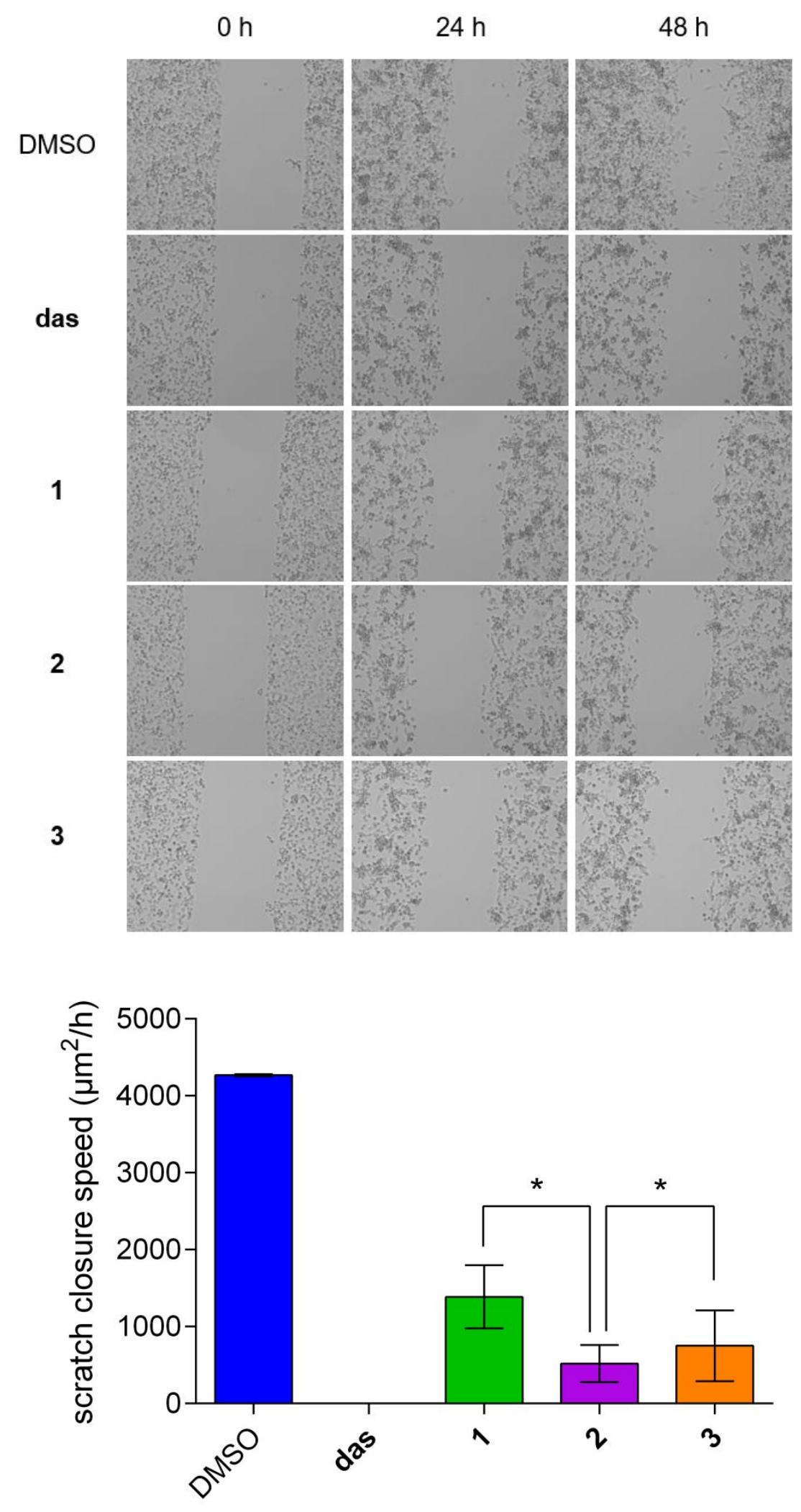
Figure S4. Wound healing assay of MDA-MB-231, images and quantification. *,$p$ : Not Significant (N. S.) using OneWay ANOVA. 

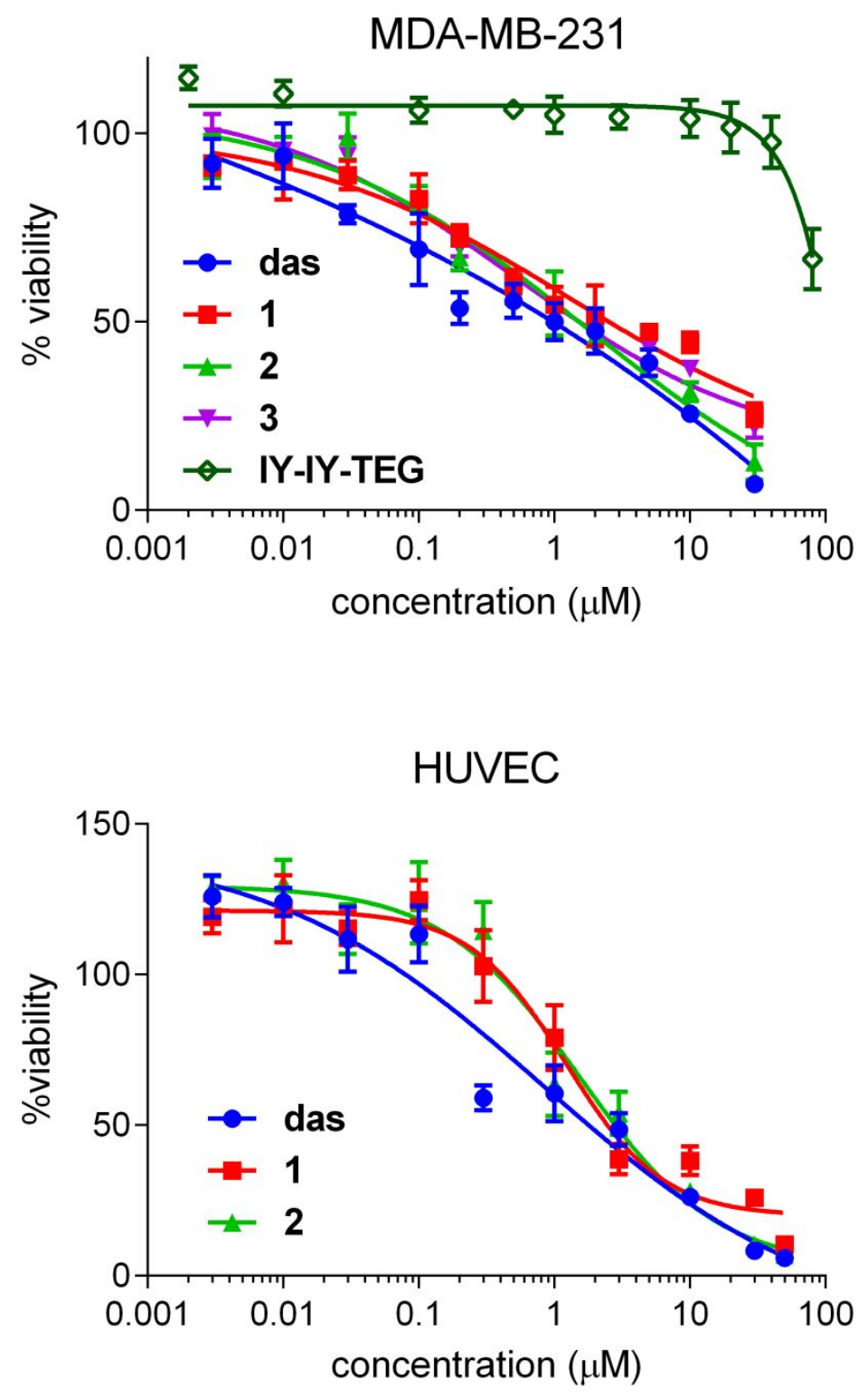

Figure S5. Cytotoxicity assay of dasatinib and conjugates on MDA-MB-231 and HUVEC cells. 


\begin{tabular}{rl|c|c|c|c|c|c|}
\hline & DMSO & \multicolumn{3}{|c|}{10} & \multicolumn{3}{c|}{11} \\
\hline conc. $(\mu \mathrm{M})$ & $0.1 \%$ & 40 & 20 & 10 & 40 & 20 & 10 \\
\hline \multirow{3}{*}{ TrkC } & & & & & & \\
& & &
\end{tabular}

Figure S6. Degradation of TrkC in NIH3T3-TrkC cells by IY-IY-PEG(n)-nutlin $(n=3,10 ; n=5,11)$ with $24 \mathrm{~h}$ incubation.

\begin{tabular}{c|c|c|c|c|c|}
\hline & \multicolumn{5}{|c|}{11 at $40 \mu \mathrm{M}$} \\
\hline $\begin{array}{c}\text { incubate } \\
\text { time (h) }\end{array}$ & 24 & 6 & 4 & 2 & 0 \\
\hline \multirow{2}{*}{ TrkC } & & & & \\
\cline { 2 - 5 } & & &
\end{tabular}

Figure S7. Time course TrkC degradation experiment with treatment of PROTACs (IY-IY-PEG5-nutlin, 11) in NIH3T3-TrkC cells. 


\section{E. References}

[1] A. Kamkaew and K. Burgess. J. Med. Chem. 2013, 56, 7608-7614.

[2] D. Chen, F. Brahimi, Y. Angell, Y. Li, J. Moscowicz, H. U. Saragovi, K. Burgess. ACS Chem. Biol. 2009, 4, 769-781.

[3] Z. Yang, S. M. Usama, F. Li, K. Burgess, Z. Li. Med. Chem. Commun. 2018, 9, 1754-1760.

[4] B. Zhao and K. Burgess. Chem. Commun. 2019, 55, 2704-2707.

[5] N. Li, N. P. Gossai, J. A. Naumann, P. M. Gordon, J. A. Piccirilli. Bioconjugate Chem. 2016, 27, 2575-2579.

[6] E. Păunescu, C. M. Clavel, P. Nowak-Sliwinska, A. W. Griffioen, P. J. Dyson, ACS Med. Chem. Lett. 2015, 6, 313317. 


\section{F. NMRs}

Compound $\mathbf{5}$

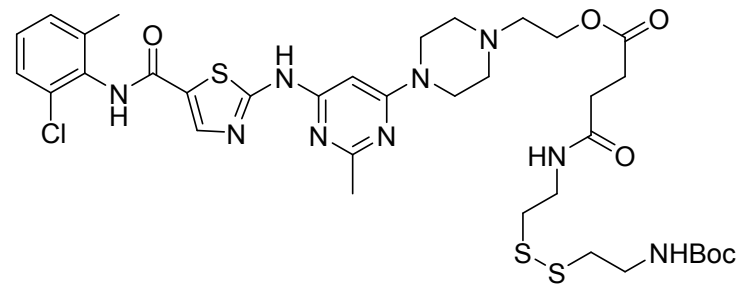

${ }^{1} \mathrm{H} N M R$ in $\mathrm{MeOD}$

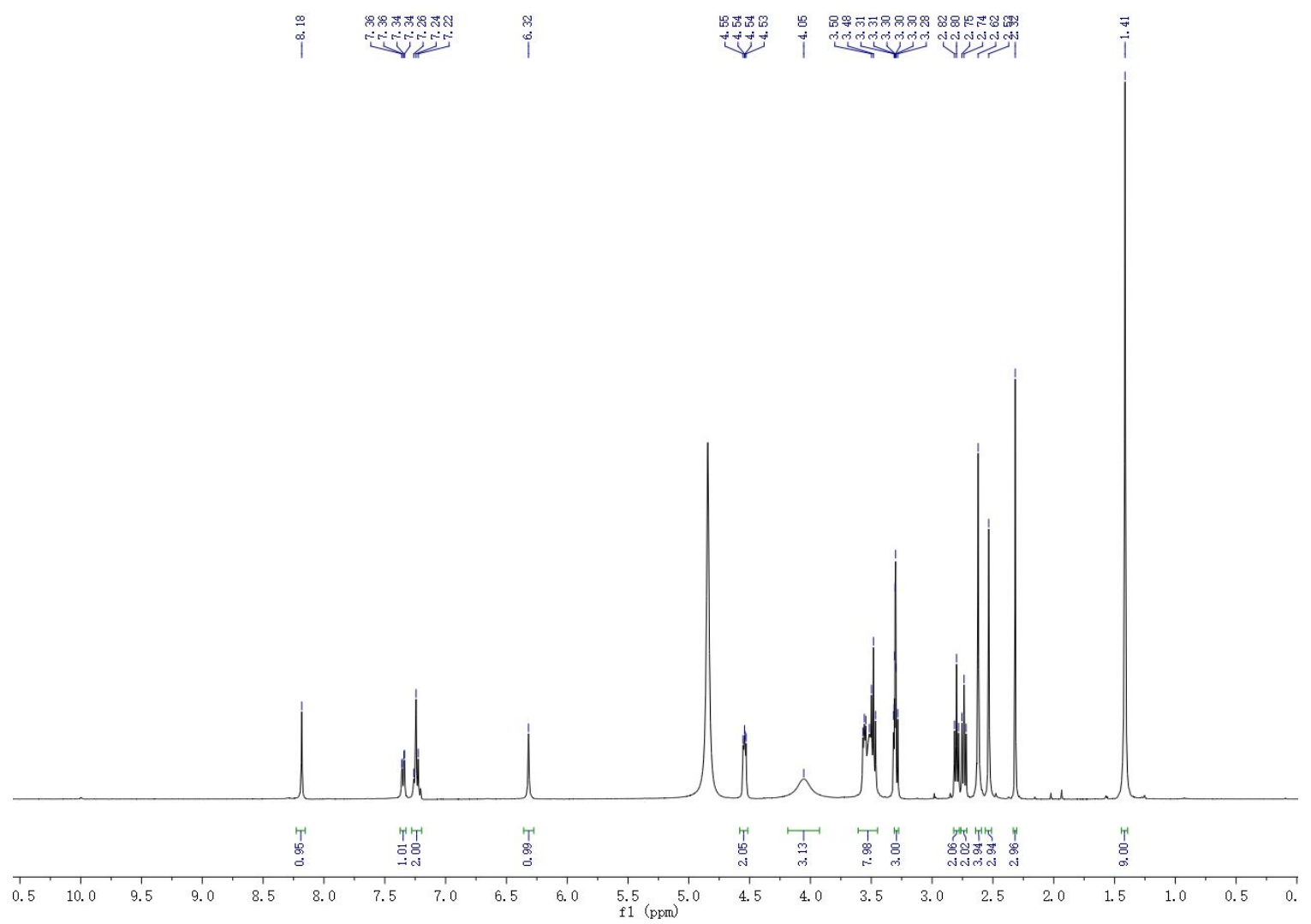


${ }^{13} \mathrm{C}$ NMR in MeOD
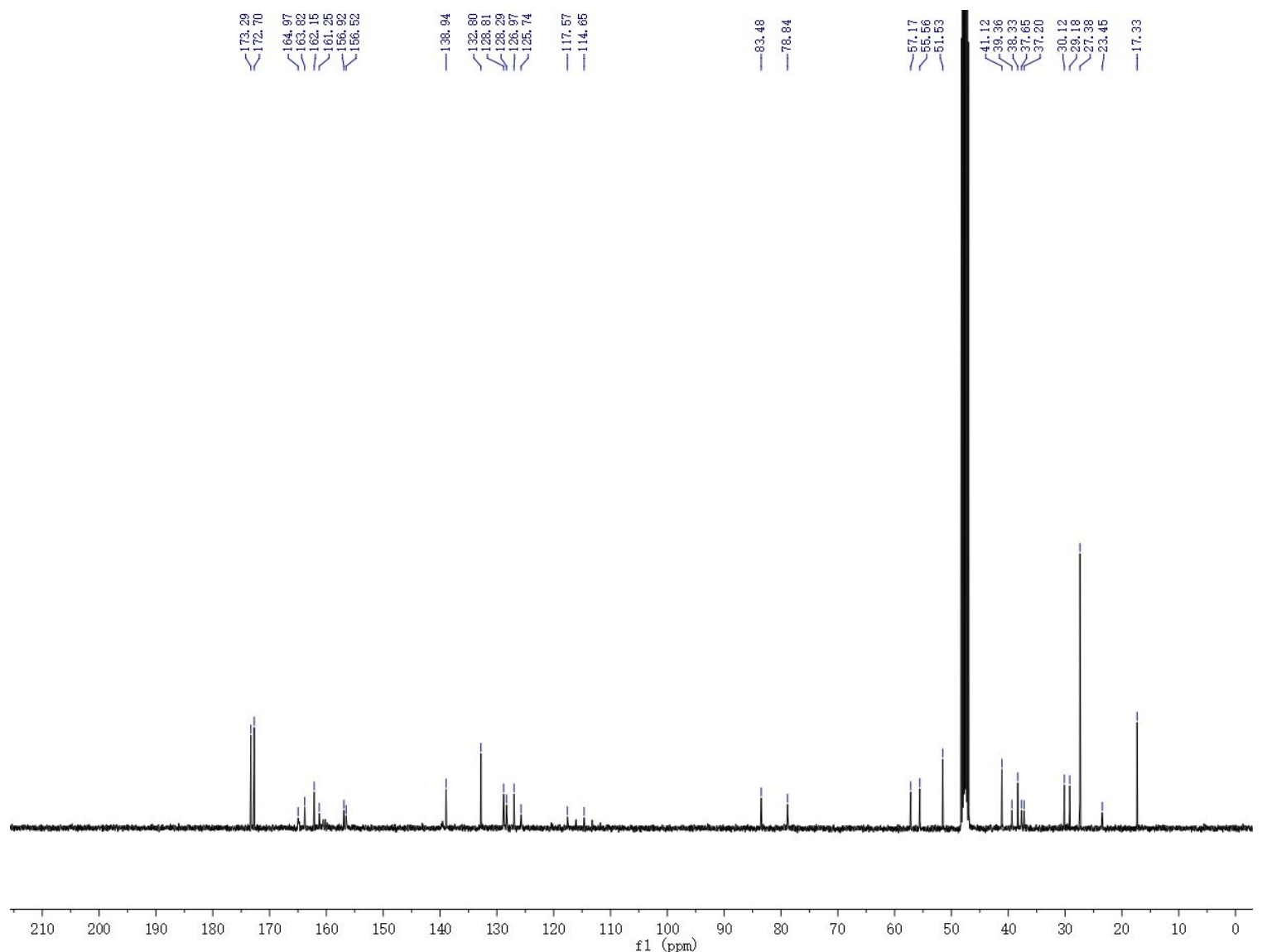


\section{Compound 6}<smiles>Cc1nc(Nc2ncc(C(=O)Nc3c(C)cccc3Cl)s2)cc(N2CCN(CCOC(=O)CCC(=O)NCCSSCCNC(=O)CCC(=O)O)CC2)n1</smiles>

${ }^{1} \mathrm{H} N M R$ in MeOD

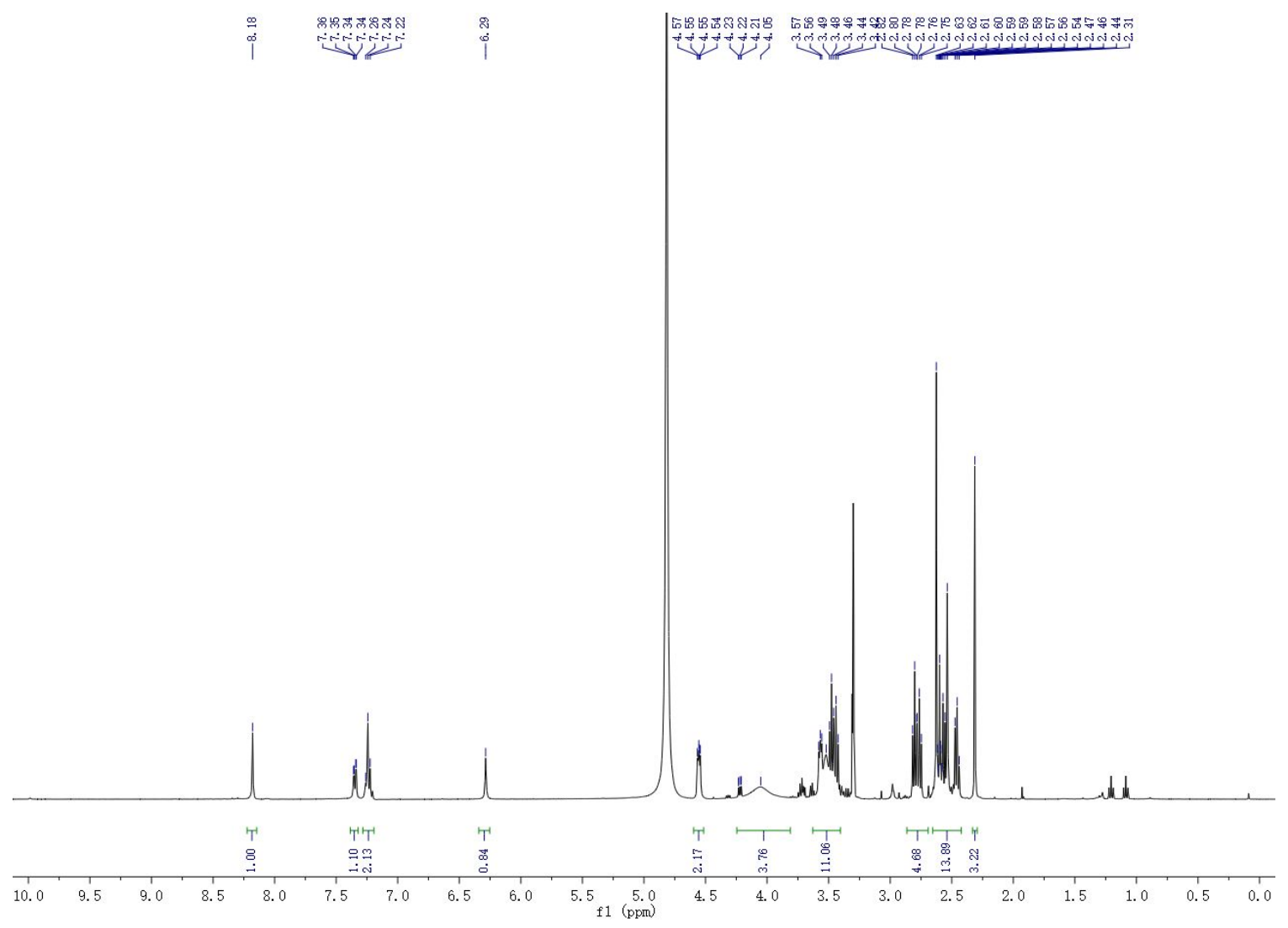


${ }^{13} \mathrm{C}$ NMR in MeOD

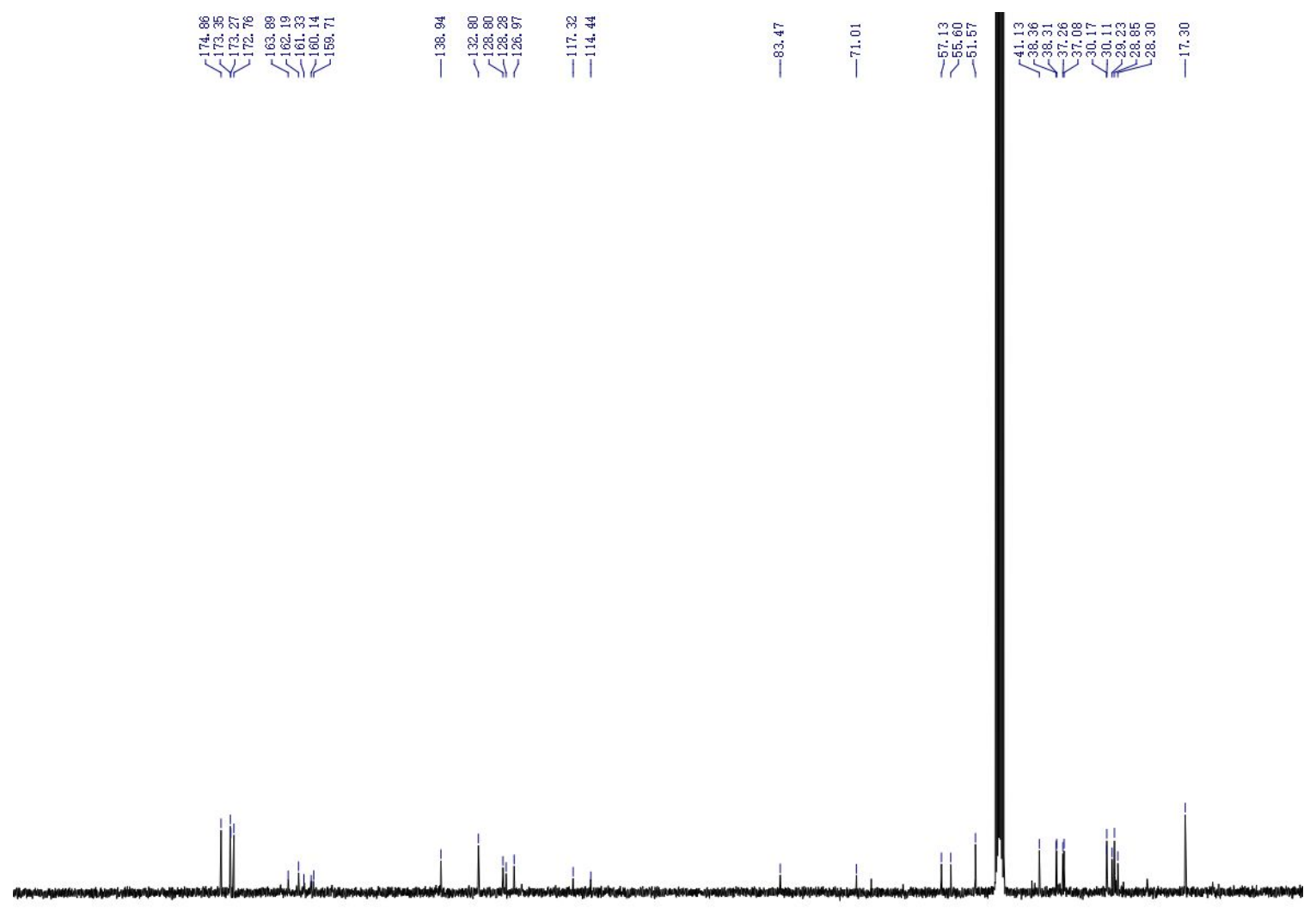

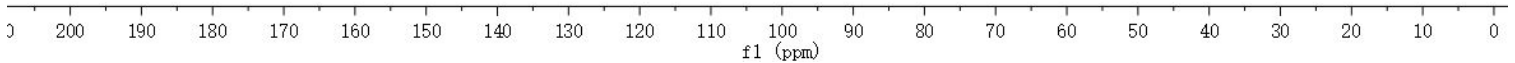




\section{Compound 1, IY-IY-Das}

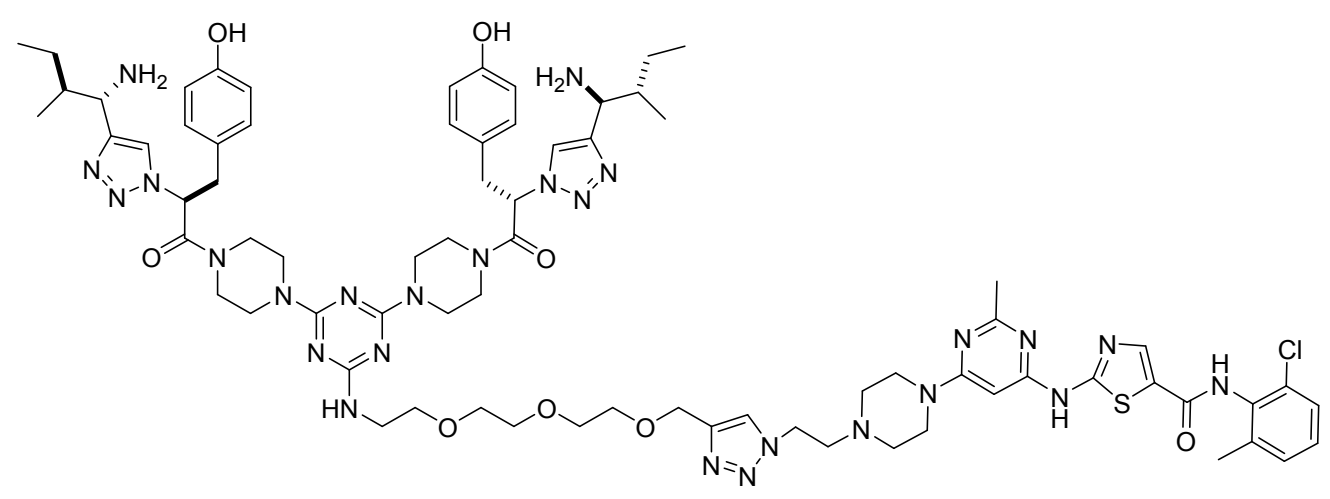

${ }^{1} \mathrm{H}$ NMR in DMSO-d 6

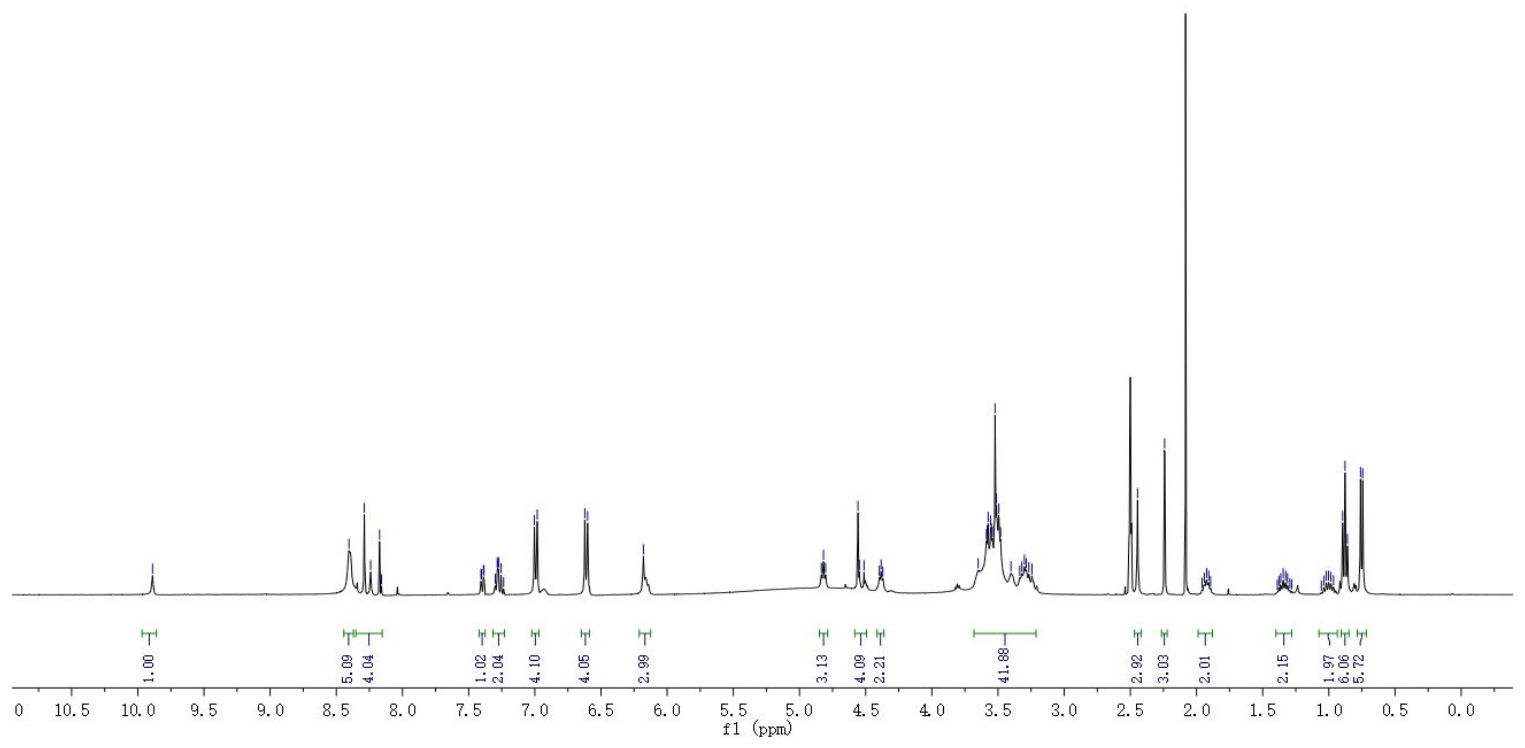


${ }^{13} \mathrm{C}$ NMR in DMSO-d 6

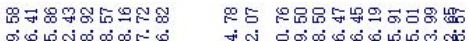

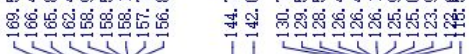

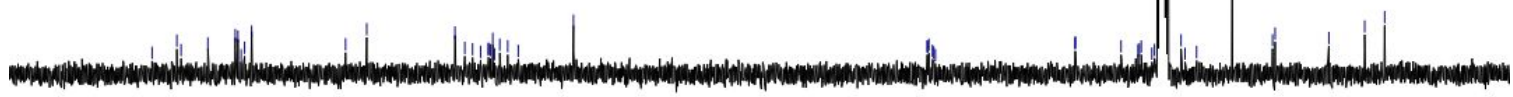

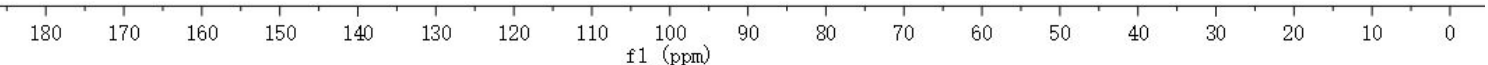




\section{Compound 2, IY-IY-SS-Das}

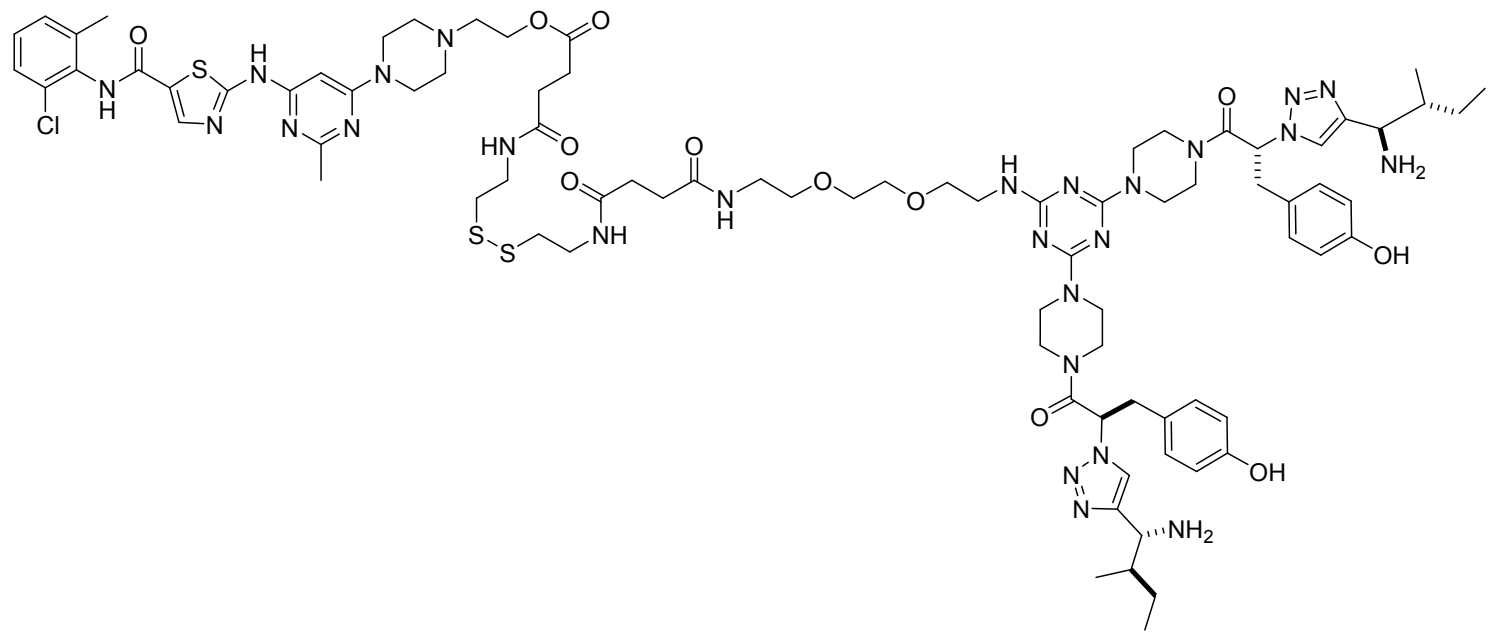

${ }^{1} \mathrm{H} N M R$ in MeOD

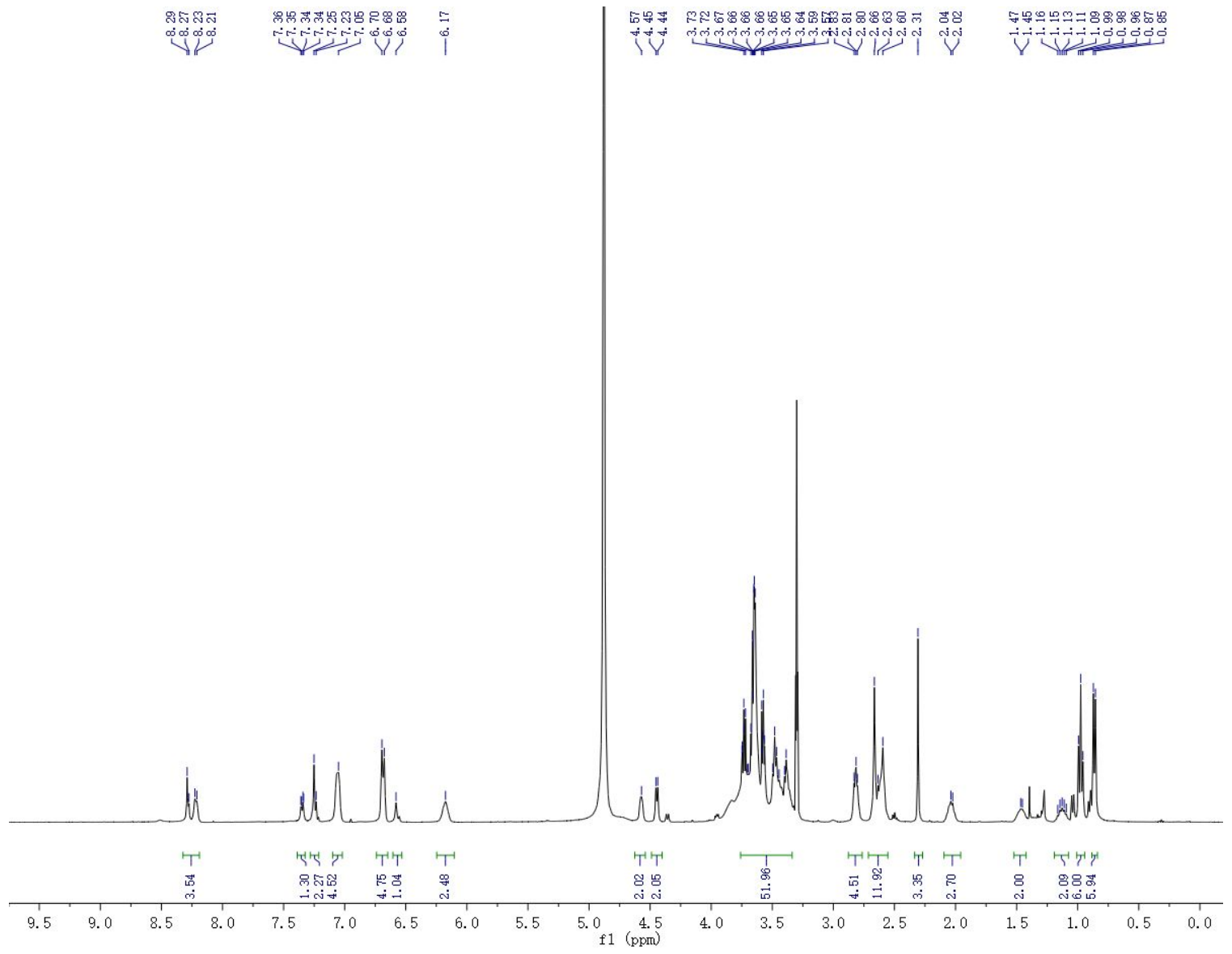


${ }^{13} \mathrm{C}$ NMR in MeOD

군

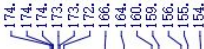

ஜ

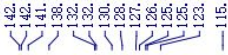

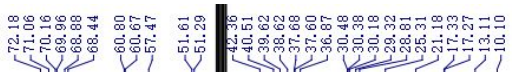

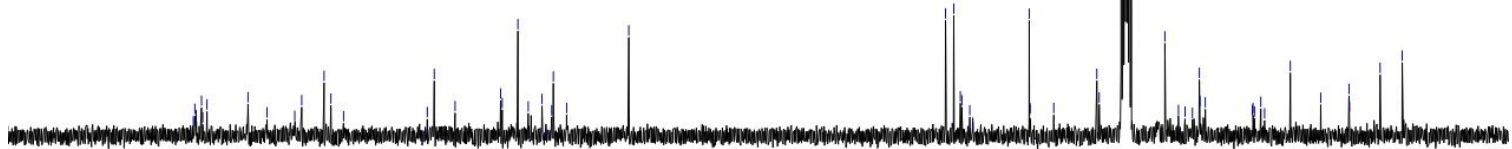

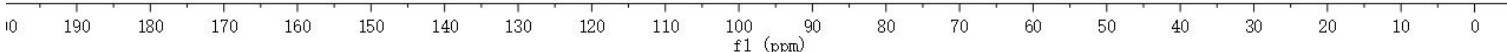




\section{Compound 3, YI-YI-SS-Das}

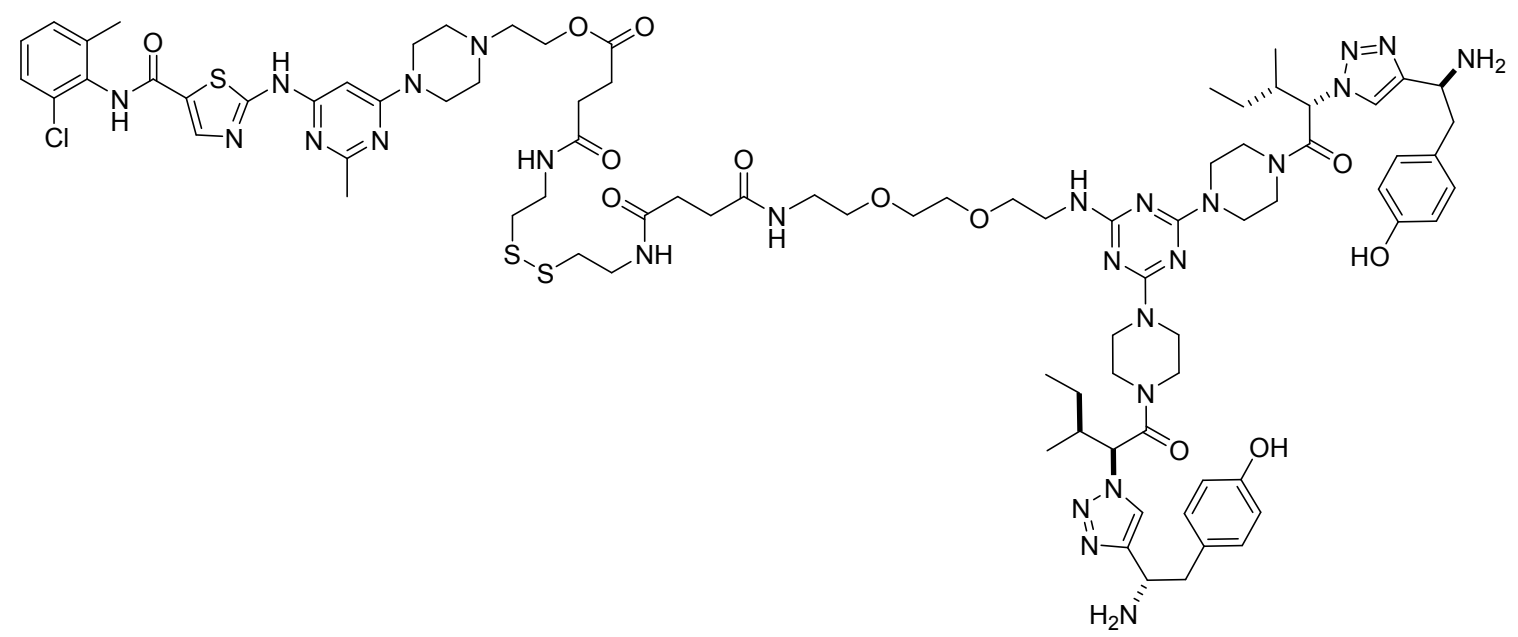

\section{${ }^{1} \mathrm{H}$ NMR in DMSO-d 6}
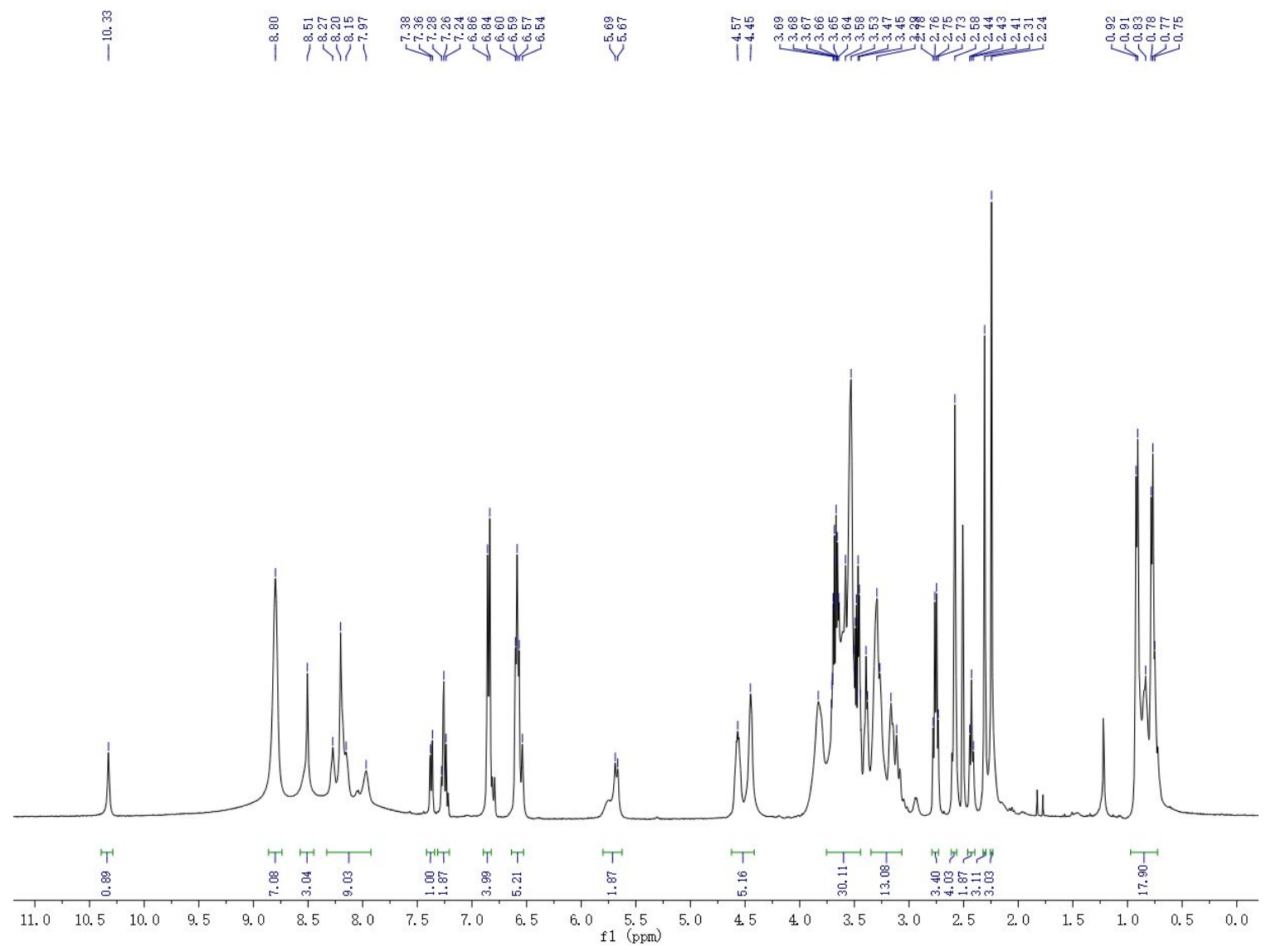
${ }^{13} \mathrm{C}$ NMR in DMSO- $d_{6}$

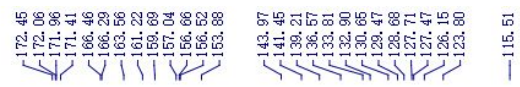

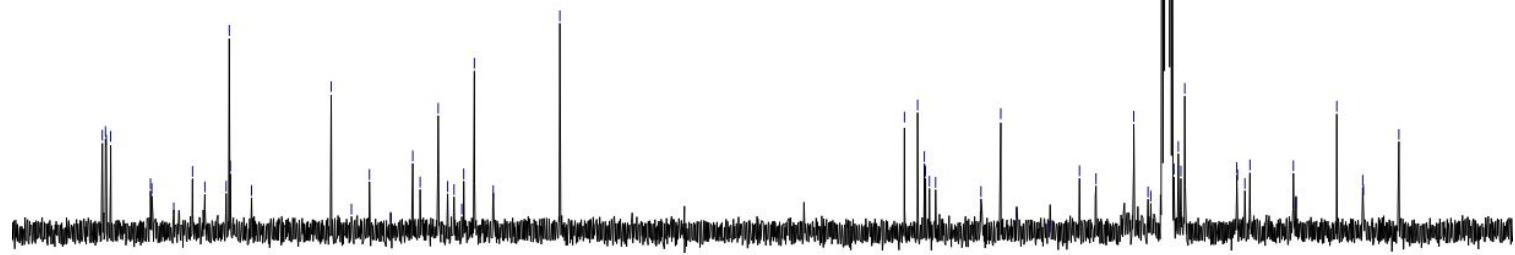

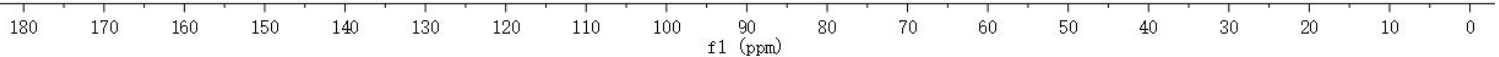




\section{Compound 4, IY-IY-pom}

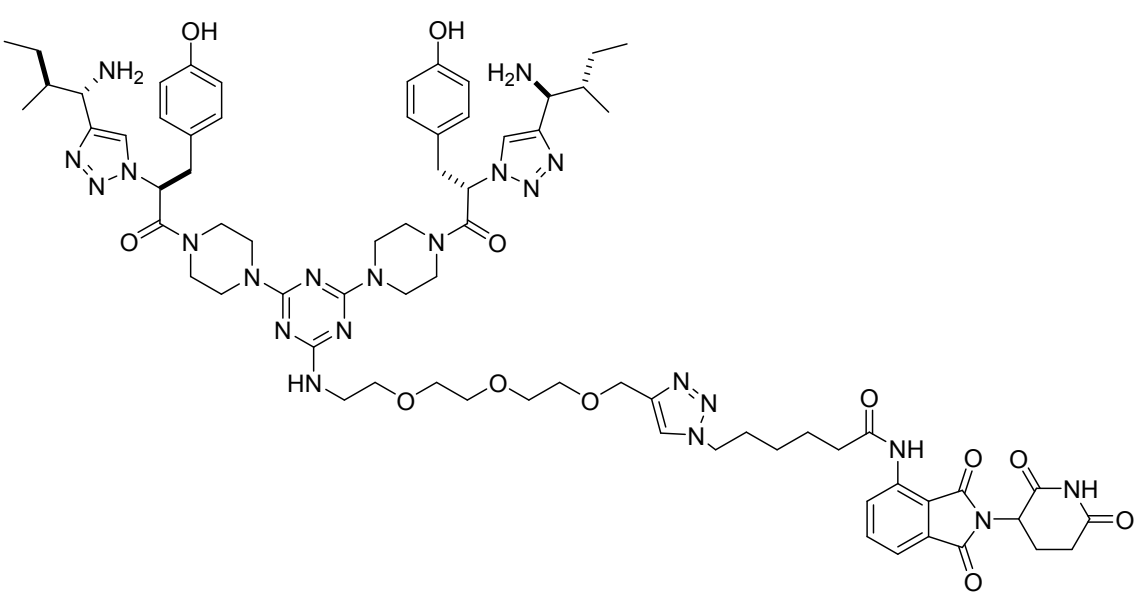

\section{${ }^{1} \mathrm{H}$ NMR in DMSO- $\mathrm{d}_{6}$}

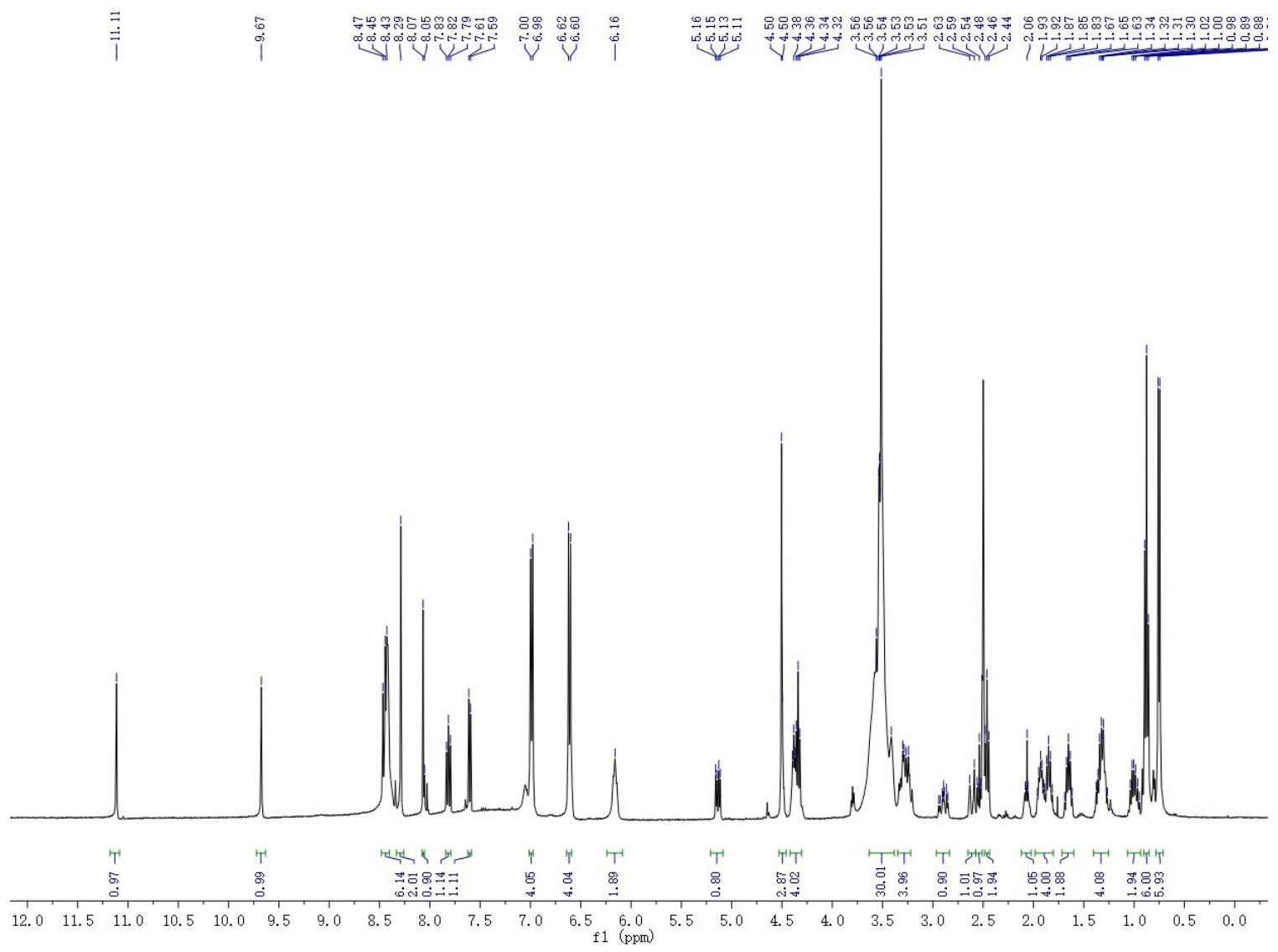


${ }^{13} \mathrm{C}$ NMR in DMSO- $\mathrm{d}_{6}$
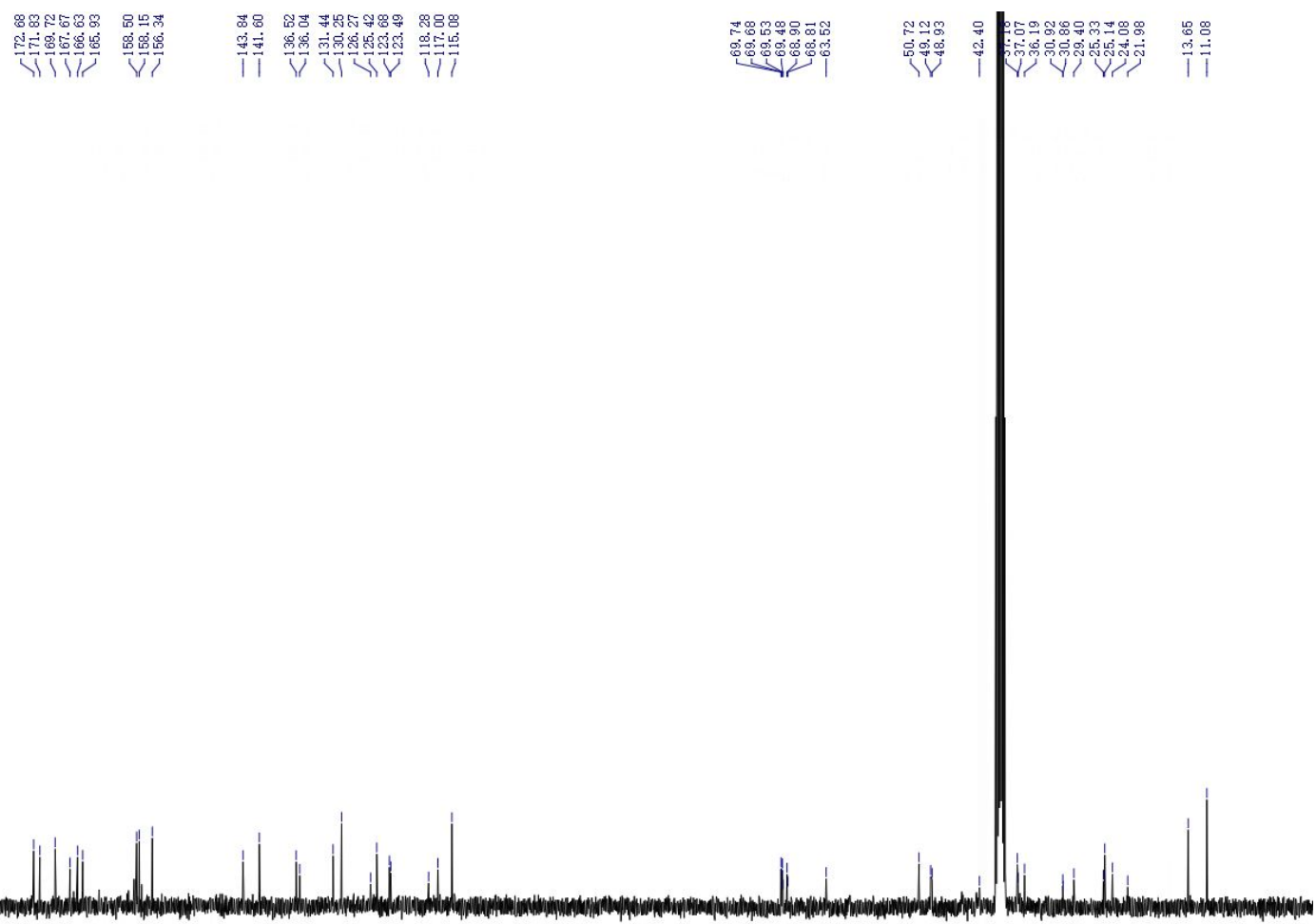

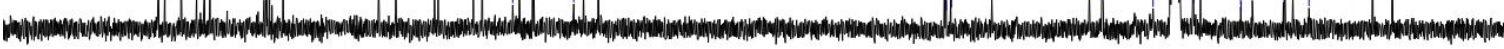

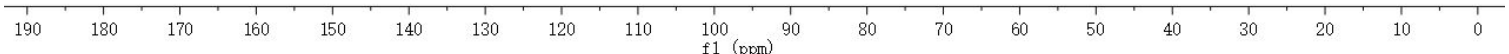




\section{Compound 10, IY-IY-PEG3-nutlin}

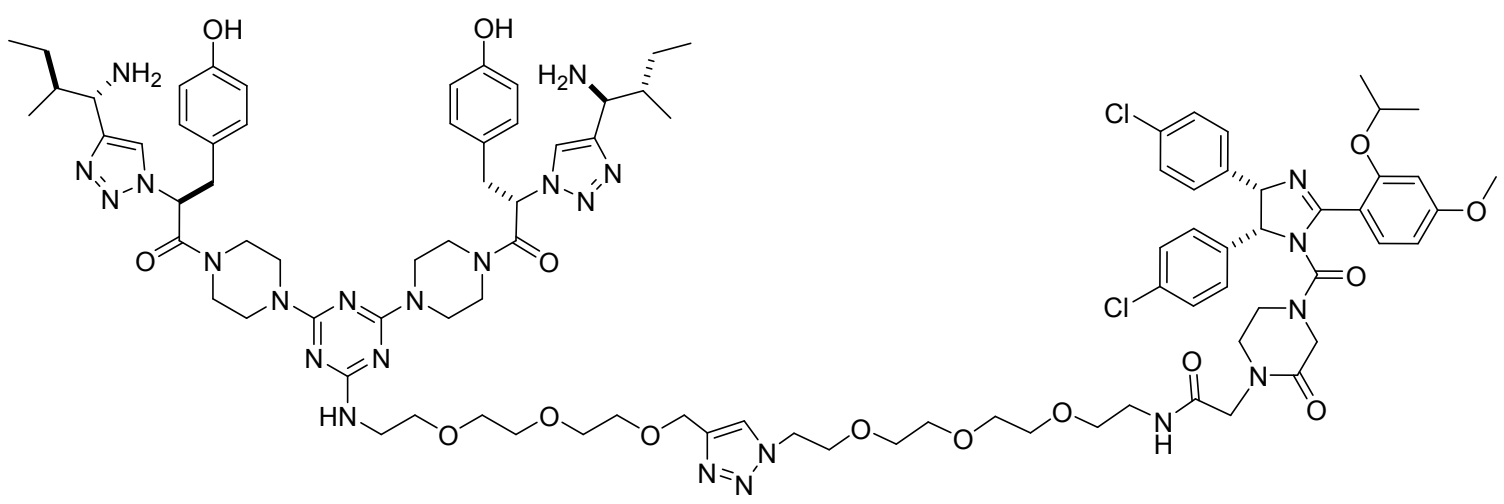

${ }^{1} \mathrm{H}$ NMR in DMSO-d 6

4⿻ำ

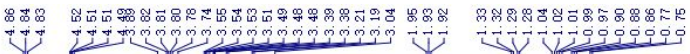

il in in

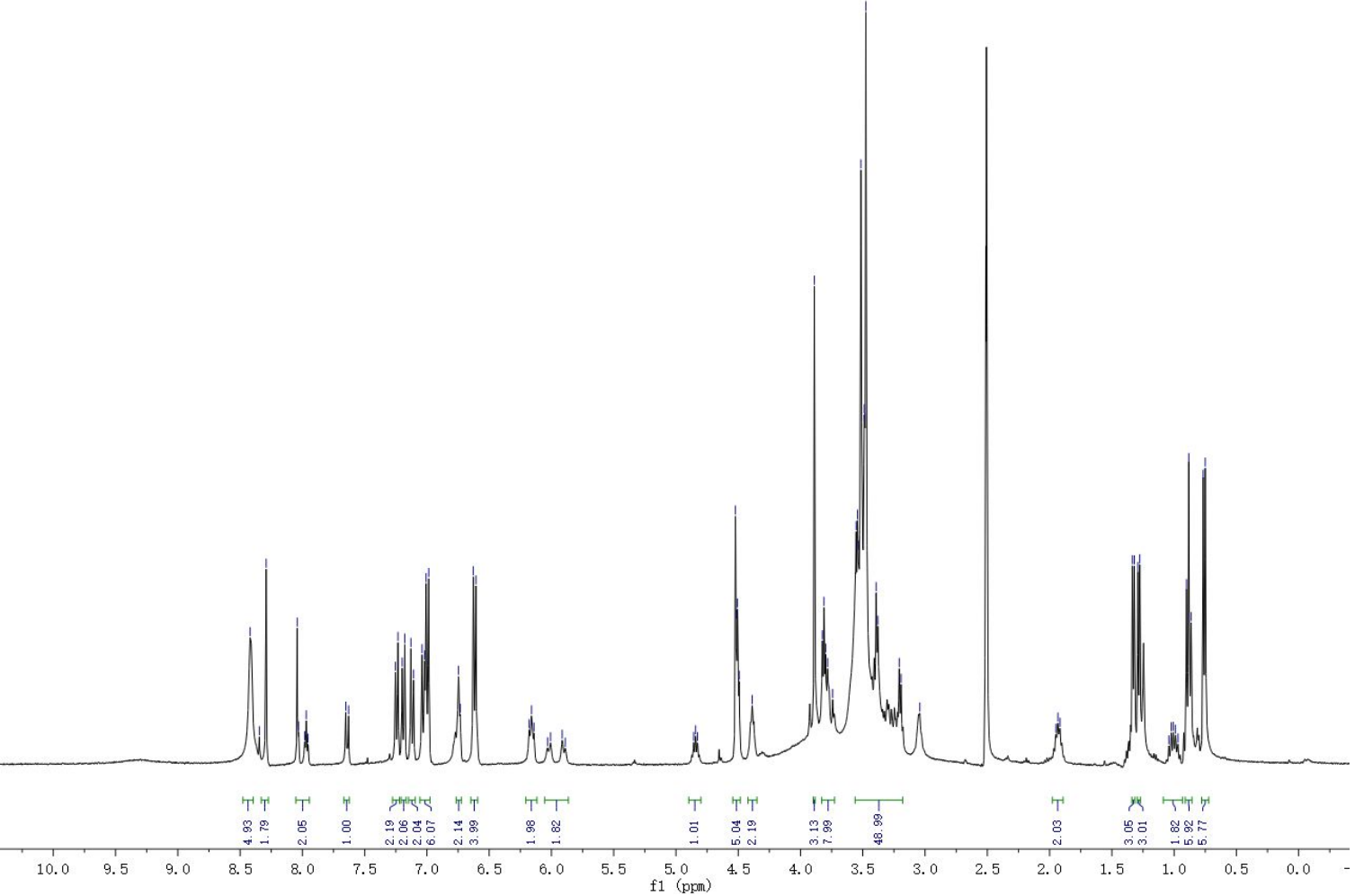




\section{Compound 11, IY-IY-PEG5-nutlin}

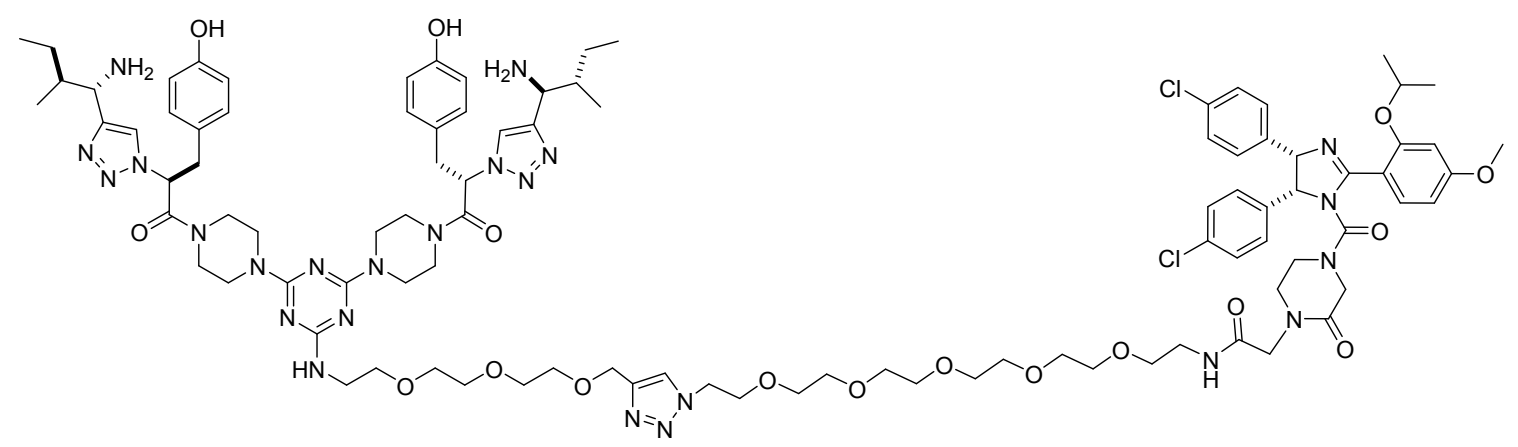

${ }^{1} \mathrm{H}$ NMR in DMSO-d 6
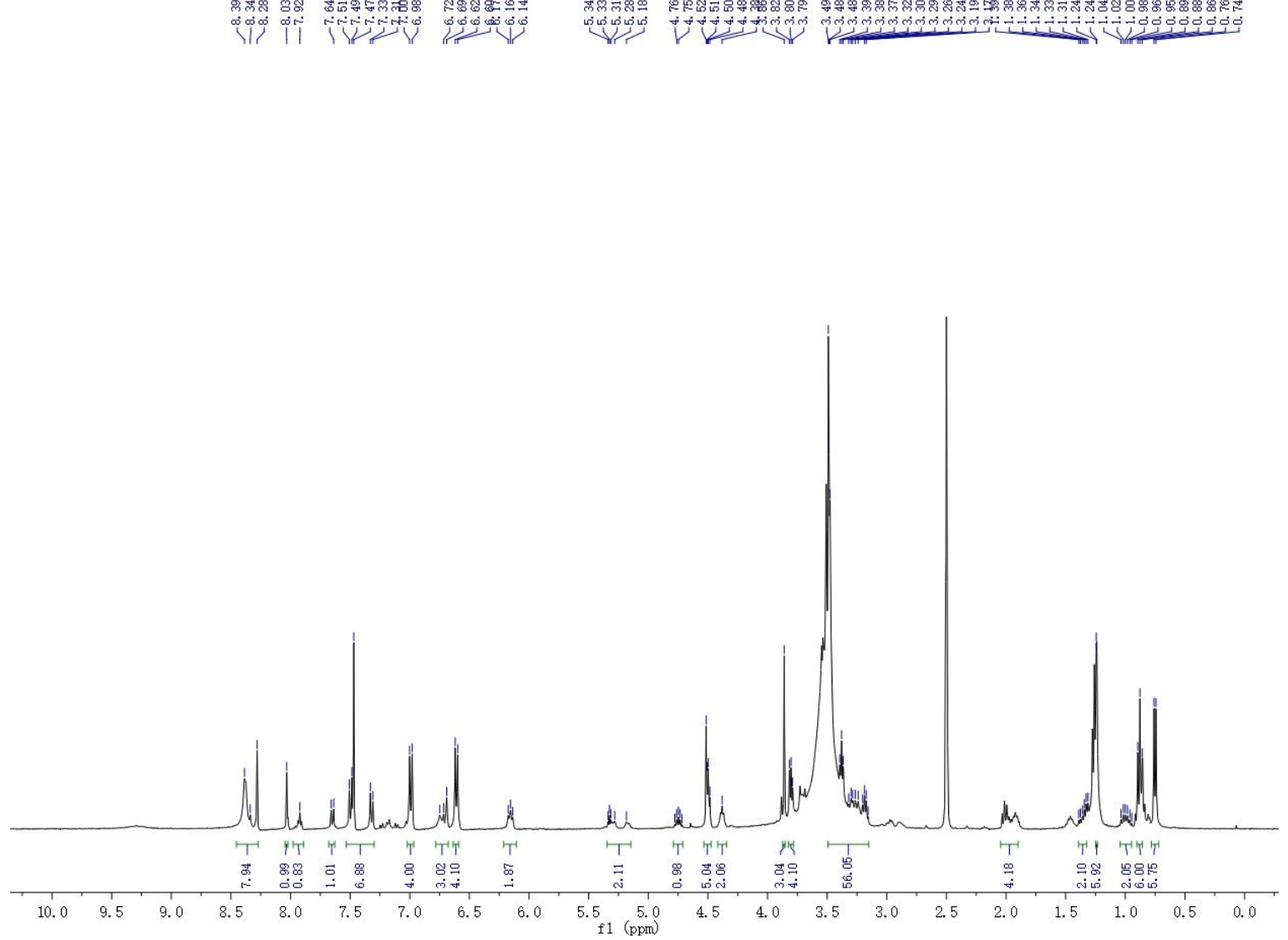